\title{
Scope Elasticity of Willingness to pay in Discrete Choice Experiments
}

\author{
Anders Dugstad $^{1} \cdot$ Kristine M. Grimsrud $^{2} \cdot$ Gorm Kipperberg $^{3}$ (D) Henrik Lindhjem ${ }^{4,5}$. \\ Ståle Navrud ${ }^{1}$
}

Accepted: 29 June 2021 / Published online: 2 August 2021

(C) The Author(s) 2021

\begin{abstract}
Sensitivity to scope in nonmarket valuation refers to the property that people are willing to pay more for a higher quality or quantity of a nonmarket public good. Establishing significant scope sensitivity has been an important check of validity and a point of contention for decades in stated preference research, primarily in contingent valuation. Recently, researchers have begun to differentiate between statistical and economic significance. This paper contributes to this line of research by studying the significance of scope effects in discrete choice experiments (DCEs) using the scope elasticity of willingness to pay concept. We first formalize scope elasticity in a DCE context and relate it to economic significance. Next, we review a selection of DCE studies from the environmental valuation literature and derive their implied scope elasticity estimates. We find that scope sensitivity analysis as validity diagnostics is uncommon in the DCE literature and many studies assume unitary elastic scope sensitivity by employing a restrictive functional form in estimation. When more flexible specifications are employed, the tendency is towards inelastic scope sensitivity. Then, we apply the scope elasticity concept to primary DCE data on people's preferences for expanding the production of renewable energy in Norway. We find that the estimated scope elasticities vary between 0.13 and 0.58 , depending on the attribute analyzed, model specification, geographic subsample, and the unit of measurement for a key attribute. While there is no strict and universally applicable benchmark for determining whether scope effects are economically significant, we deem these estimates to be of an adequate and plausible order of magnitude. Implications of the results for future DCE research are provided.
\end{abstract}

Keywords Discrete choice experiments - Construct validity $\cdot$ Willingness to pay $\cdot$ Scope test $\cdot$ Elasticity $\cdot$ Economic significance $\cdot$ Stated preferences

\section{Gorm Kipperberg}

gorm.kipperberg@uis.no

1 School of Economics and Business, Norwegian University of Life Sciences, Ås, Norway

2 Research Department, Statistics Norway, Oslo, Norway

3 UiS Business School, University of Stavanger, 4036 Stavanger, Norway

4 Menon Centre for Environmental and Resource Economics, Oslo, Norway

5 Norwegian Institute for Nature Research (NINA), Oslo, Norway 


\section{Introduction}

Sensitivity to scope in nonmarket valuation refers to the property that people are willing to pay more for a higher quality or quantity of a nonmarket public good (Carson et al. 2001; Freeman et al. 2014; Mariel et al. 2021). Establishing significant scope sensitivity has been an important check of validity and a point of contention for decades in stated preferences (SP) research, primarily in contingent valuation (CV) surveys (Kahneman 1986; Mitchell and Carson 1989; Kahneman and Knetsch 1992; Desvousges et al. 1992; Diamond and Hausman 1994; Whitehead et al. 1998; Berrens et al. 2000; Heberlein et al. 2005; Lew and Wallmo 2011; Hausman 2012; Kling et al. 2012; Haab et al. 2013; Whitehead 2016). ${ }^{1}$

At the one extreme, some researchers have claimed general methodological invalidity in light of the failure of some studies to establish statistically significant scope effects (Hausman 2012). Recently, however, several authors have made compelling arguments to the effect that the scope sensitivity and validity of a study cannot be assessed purely on the basis of tests of statistical significance (e.g., Amiran and Hagen 2010; Whitehead 2016; Lopes and Kipperberg 2020). The extent to which estimated scope effects are economically significant (McCloskey and Ziliak 1996; Thorbecke 2004) may be equally important. Related to economic significance are the concepts of adequacy, i.e., whether the estimated scope effects exceed a minimum threshold, and plausibility, i.e., whether the estimates are believable for the particular empirical context (Arrow et al. 1994; Whitehead 2016). ${ }^{2}$

A specific measure proposed for assessing the economic significance of sensitivity to scope in CV studies is scope elasticity of willingness to pay (WTP) (Amiran and Hagen 2010). This elasticity measures the percentage change in WTP for a nonmarket good relative to the percentage change in its quantity or quality. Amiran and Hagen (2010) demonstrate that scope elasticities need only be greater than zero and less than one in the case of strictly convex neoclassical preferences. A resulting challenge is that elasticities close to zero may be difficult to detect statistically. Whitehead (2016) elaborates on the economic intuition underlying the concept of scope elasticity and applies it in a re-assessment of several CV studies that initially had their scope sensitivity questioned. He argues that the implied scope elasticities of WTP in these studies are within a plausible range and satisfy economic significance. ${ }^{3}$

The issue of sensitivity to scope has also been explored in the discrete choice experiment (DCE) literature, but to a much lesser extent than for CV (Layton and Brown 2000; Lew and Wallmo 2011; Rakotonarivo et al. 2016; Johnston et al. 2017). As in CV studies, sensitivity to scope in DCEs implies that people are willing to pay more for a larger quantity or better quality of a good. For a good, as opposed to a bad, this is usually indicated as higher attribute levels, all else held equal. Depending on the experimental design, variation in the levels of quantitative attributes facilitates scope sensitivity examination through the estimation of indirect utility functions with linear and non-linear functional forms. For

\footnotetext{
1 See Lopes and Kipperberg (2020) for a recent overview.

${ }^{2}$ Estimated scope effects in economic models can be statistically significant without being economically significant and vice versa. In the latter case, lack of statistical precision may lead to failure to reject the null hypothesis of no impact, even when point estimates are indicative of economic significance. Ideally, of course, a well-designed study with sufficient power can establish both statistical and economic significance.

3 The scope elasticity concept can be applied generally to assessment of the sensitivity of welfare measures to scope, including both WTP and willingness to accept (WTA) measures. For simplicity, we refer only to the term scope elasticity of WTP here.
} 
example, Layton and Brown (2000), estimate a piecewise linear indirect utility function to test whether WTP to avoid larger forest losses due to climate change is higher than WTP to avoid smaller losses. Lew and Wallmo (2011) perform scope tests across a number of protected endangered species as well as their protection levels. Both studies establish statistically significant scope effects. Neither study discusses adequacy, plausibility, or economic significance, though Layton and Brown (2000) refer to their results as "economically sensible" and "economically reasonable". 4

It is important from both a methodological point of view and a policy perspective to further develop and include scope tests in DCE studies as well as in CV research. Methodologically, scope sensitivity continues to be discussed in relation to SP validity. As pointed out in the SP guidance by Johnston et al. (2017, p. 374): "Underlying the challenge for SP validity testing is the lack of general agreement on whether results from individual studies (or sets of studies) should be interpreted as evidence for or against the validity of the method in general. Recognizing this lack of agreement over what constitutes an acceptable validity test for SP studies, we recommend continued investigation of both current and new tests as an important area for future research." From a practical resource management perspective, policymakers are typically interested in assessing different policy alternatives and associated attributes varying in magnitude (e.g., degree of environmental protection), with increasing opportunity costs. If the social benefits of the policy should turn out to be invariant to the public good provision levels, the optimal decision would be simple. The policymakers should choose the lowest cost alternative. In many circumstances, such a finding would seem implausible and not be useful for decision-making.

In this paper, we investigate scope effects through the lens of the scope elasticity of WTP concept. To our knowledge, no other DCE study has used this analytical framework. We provide a theoretical discussion, methodological perspectives, and a unique empirical application. We begin by formalizing scope elasticity of WTP both generally and specifically in the DCE context (Sect. 2). Then we review a selection of DCE studies from the environmental valuation literature and derive their implicit elasticity estimates (Sect. 3). The literature analysis leads to the following three observations: (i) explicit investigations of scope sensitivity in DCE studies seem uncommon; (ii) many studies assume unitary elastic scope sensitivities through their choice of restrictive functional form; and (iii) studies that utilize flexible functional forms tend to find inelastic effects, consistent with diminishing marginal utility from attribute improvements.

Following the literature discussion, we apply the scope elasticity of WTP concept to study preferences for expanding renewable energy in Norway (Sects. 4 and 5). We provide baseline results for two quantitative attributes (renewable energy production and wind power expansions) and investigate whether elasticity estimates vary across model specifications, geographic subsamples with different levels of familiarity and exposure, and experimental variation in the unit of measurement of the quantitative wind power attribute. This analysis is generally motivated by the lack of attention to DCE scope effects revealed by the literature review. More specifically, the exploration of familiarity and exposure is motivated by the existing literature on habituation to environmental change (e.g., Wilson and Dyke 2016; Zerrahn 2017) while the exploration of unit of measurement is motivated

\footnotetext{
4 The presence of scope sensitivity SP in studies can be assessed by means of external or internal tests. In DCEs, scope significance is typically identified by means of a combination of within- and betweenrespondent variation in attribute levels (e.g., Layton and Brown 2000). The split-sample, external scope test in the DCE of Lew and Wallmo (2011) is an exception.
} 
by emerging research on choice architecture and attribute representation (e.g., Hertwig and Grüne-Yanoff 2017; Ungemach et al. 2018). Both of these strands of research are relevant to the scope effects observed.

Overall, the analyses in this paper show that scope sensitivity can vary between attributes and across conceptual, methodological, and empirical dimensions of studies. Section 6 provides a summary of findings and concluding reflections with specific recommendations for future research.

\section{Conceptual Framework}

The concept of scope elasticity of WTP was first proposed by Amiran and Hagen (2010) to address the economic significance of scope sensitivity in CV research. Whitehead (2016) then applied the concept in simulation analysis and empirical illustrations. Existing CV studies that have subsequently reported scope elasticity estimates include Burrows et al. (2017), Borzykowski et al. (2018), and Lopes and Kipperberg (2020).

A major appeal of the scope elasticity of WTP framework is that it provides a unit-free measure of the ceteris paribus responsiveness of an endogenous variable of interest (in this case, WTP) to a change in an exogenous variable (in this case, environmental quality). As such, it is similar to other important elasticity measures in economics (e.g., own-price elasticisty of demand; input-price elasticity of supply; income elasticity of WTP). Specifically, the scope elasticity of WTP is defined as the ratio of percentage change in WTP to the percentage change in environmental quality. A scope elasticity of zero signals absence of impact, or no scope effect, whereas a scope elasticity of one means proportional responsiveness. Elasticity estimates within the 0 to 1 interval imply less than proportional, i.e., inelastic, impact. Such an elasticity would be expected under neoclassical microeconomic convexity priors regarding the trade-off between market and nonmarket goods (Amiran and Hagen 2010; Whitehead 2016). For example, a scope elasticity of 0.4 suggests that a $10 \%$ increase in environmental quality is associated with a $4 \%$ increase in WTP. However, the scope elasticity could also be greater than one, suggesting disproportionally large, i.e., elastic, responsiveness. Elastic WTP responsiveness to change in scope is consistent with increasing marginal utility of an economic good or increasing disutility from an economic bad (e.g., Layton and Brown 2000).

\subsection{Defining the Scope Elasticity of WTP in General}

Let $W T P=\operatorname{WTP}(q, z)$ represent a general value function for a representative consumer, where $q$ is a scalar measure of the level of environmental quality and $z$ is a vector of other factors influencing the consumer's valuation (including income). The scope elasticity of WTP $\left(E_{W T P}\right)$ is then given by:

$$
E_{W T P} \equiv \frac{\% \Delta W T P(q, z)}{\% \Delta q}=\left(\frac{\partial W T P(q, z)}{\partial q}\right) \cdot\left(\frac{q}{W T P(q, z)}\right)
$$

For a non-marginal improvement in environmental quality, say from $q^{0}$ to $q^{1}$, where $q^{1}>q^{0}$, with associated change in WTP from $W T P^{0}$ to $W T P^{1}\left(W T P^{1} \geq W T P^{0}\right)$, the midpoint formula can be utilized to define a scope arc-elasticity $\left(\bar{E}_{W T P}\right)$ as follows: 


$$
\bar{E}_{W T P} \equiv \frac{\% \Delta W T P(q, z)}{\% \Delta q}=\left(\frac{\Delta W T P(q, z)}{\Delta q}\right) \cdot\left(\frac{\bar{q}}{\overline{W T P}}\right)
$$

where $\Delta q=q^{1}-q^{0}>0, \Delta W T P=W T P^{1}-W T P^{0} \geq 0$, and $\bar{q}$ and $\overline{W T P}$ are, respectively, average environmental quality $\left(\frac{q^{0}+q^{1}}{2}\right)$ and average WTP $\left(\frac{W T P^{0}+W T P^{1}}{2}\right)$.

\subsection{Defining Scope Elasticities in DCE}

Scope sensitivity in DCEs means that people's WTP for a specific attribute (good/bad) is (increasing/decreasing) in its level, all else held equal (Mariel, et al. 2021). However, multi-attribute discrete choice situations are typically motivated from a random utility model (RUM) framework, not via a direct valuation function, as above. Therefore, let indirect utility $(U)$ be represented by $U=V+\varepsilon$, where $V$ is the deterministic component and $\varepsilon$ is the random component (see e.g., Hensher et al. 2005). For the sake of simplicity, we ignore the latter term and focus on deterministic indirect utility. Let $V=V(\boldsymbol{p}, \boldsymbol{q}, M)$ be a generalized deterministic indirect utility component, where $\boldsymbol{p}$ is an exogenous price vector, $\boldsymbol{q}$ represents nonmarket goods and amenities exogenously provided (including various environmental quantity and quality attributes), and $M$ is exogenous consumer income. The utility an individual derives from any given policy or resource management scenario, say alternative $j$, is given by $V_{j}\left(\boldsymbol{p}, \boldsymbol{q}_{j}, M-F_{j}\right)$, where $F_{j}$ is the fee or tax payment for that scenario. Faced with $J$ mutually exclusive alternatives, the consumer is assumed to prefer the alternative that yields maximum indirect utility, meaning that alternative $i$ is chosen provided $V_{i}\left(\boldsymbol{p}, \boldsymbol{q}_{i}, M-F_{k}\right)>V_{j}\left(\boldsymbol{p}, \boldsymbol{q}_{j}, M-F_{j}\right), \forall i \neq j$.

The ceteris paribus marginal willingness to pay (MWTP) for a change in the level of a specific attribute, say attribute $s\left(q_{s} \in \boldsymbol{q}\right)$, is given by the marginal rate of substitution $(M R S)$ between that attribute and the consumer's money income:

$$
\operatorname{MWTP}\left(q_{s}\right)=M R S_{q_{s}, M}=\frac{\partial V(\cdot) / \partial q_{s}}{\partial V(\cdot) / \partial M}
$$

However, DCE researchers are often interested in non-marginal changes in amenity or attribute levels due to changes in public policy and management regimes. We therefore consider discrete changes in $\boldsymbol{q}$ and associated changes in WTP implied by the indirect utility given above. Let $\Delta_{s}^{A}=q_{s}^{A}-q_{s}^{0}$ and $\Delta_{s}^{B}=q_{s}^{B}-q_{s}^{0}, \Delta_{s}^{B}>\Delta_{s}^{A}$ represent two different discrete increases in the level of attribute $s$, where both these increases are considered improvements. The two associated WTP measures $\left(W T P^{\mathrm{A}}\right.$ and $\left.W T P^{\mathrm{B}}\right)$ are defined implicitly from the indirect utility function in the following manner:

$$
V\left(\boldsymbol{p}^{0}, \boldsymbol{q}^{0}, M\right)=V\left(\boldsymbol{p}^{0}, \boldsymbol{q}^{j}, M-W T P^{j}\right), j=A \text { or } B
$$

Subsequently, a scope arc-elasticity of WTP can be defined analogously to Eq. (2) as:

$$
\bar{E}_{W T P} \equiv \frac{\% \Delta W T P}{\% \Delta q_{s}}=\left(\frac{W T P^{B}-W T P^{A}}{\left(W T P^{B}+W T P^{A}\right) / 2}\right) /\left(\frac{\Delta_{s}^{B}-\Delta_{s}^{A}}{\left(\Delta_{s}^{B}+\Delta_{s}^{A}\right) / 2}\right)
$$


For the linear specification of the deterministic indirect utility often employed in DCE research, that is, $V_{j}=\alpha_{j}+\boldsymbol{\beta}_{q} \boldsymbol{q}_{j}+\beta_{M}\left(M-F_{j}\right), \operatorname{MWTP}\left(q_{s}\right)=\beta_{q_{S}} / \beta_{M}$ and $\bar{E}_{W T P}=1 .^{5}$ This means that the estimated scope elasticity is equal to one provided that the estimated $M W T P$ is statistically significant and greater than zero. Since most researchers would agree that proportional responsiveness in a welfare estimate with respect to scope, i.e., $\bar{E}_{W T P}=1$, is economically significant, the restrictive linear functional form is meaningless for the purpose of attempting to distinguish between statistical and economic significance of scope effects. In order to explore such distinction, it is therefore necessary to employ more flexible functional forms.

\subsection{Adequate, Plausible, and Economically Significant Scope Sensitivity}

Amiran and Hagen (2010) show that neoclassical utility functions with strictly convex preferences have scope elasticity bounded by zero and one (Proposition 1, p. 59). Furthermore, $\bar{E}_{W T P}=1$ implies perfect substitution between environmental quality and market goods, whereas $\bar{E}_{W T P}=0$ suggests a perfectly complementary relationship. Importantly, many well-behaved preference representations can imply "arbitrarily small" scope elasticities. These results have important implications for empirical research. First, any given application may reveal relatively moderate, but legitimate, scope effects. Second, when the underlying scope sensitivity is low in the true data-generating process, it is more challenging to statistically distinguish scope elasticity estimates from zero.

Whitehead (2016) points out that the panel of experts formed by the National Oceanic and Atmospheric Administration (NOAA) to assess the CV method (Arrow et al. 1993) was as much concerned with economic significance as with statistical significance. Specifically, the NOAA panel was concerned with the adequacy or plausibility of estimated scope effects in CV studies (Arrow et al. 1993, 1994). Whitehead (2016) interprets adequacy as a sufficiency condition (i.e., a minimum threshold criterion). While the literature has yet to establish such a condition, it is evident from the conceptual analysis in Amiran and Hagen (2010) that it could be arbitrarily close to zero. In a follow-up to Arrow et al. (1993), Arrow et al. (1994) provide the following clarification: "Had the panel thought that something as straightforward as statistical measurability were the proper way to define sensitivity, then we would (or should) have opted for language to that effect. A better word than 'adequate' would have been 'plausible': A survey instrument is judged unreliable if it yields estimates which are implausibly unresponsive to the scope of the insult. This, of course, is a judgment call, and cannot be tested in a context-free manner". In line with this sentiment, Whitehead (2016) favors using a case-by-base examination of whether scope effects are "plausible", "believable" or "within the realm of possibility". This recommendation is supported by his Monte Carlo scope elasticity simulations, which indicate that $95 \%$ of the draws lie between 0.630 and 0.998 in the case of a simple linear WTP function and between 0.177 and 0.971 in the case of a quadratic WTP function. A re-assessment of several previously contested CV studies reveals plausible scope elasticities between 0 and 1 (Whitehead, 2016). ${ }^{6}$

\footnotetext{
5 The proof of this claim is provided in the Appendix.

6 Burrows et al. (2017) judge scope elasticities of less than 0.2 as implausible and inadequate. This is an ad hoc threshold without a clear theoretical or empirical foundation. While most scope elasticity estimates reported in Sects. 3 and 5 exceed 0.2, we do not believe researchers should utilize a strict threshold value in making inference with regard to the plausibility, adequacy, or economic significance of scope effects.
} 


\section{Scope Elasticities in Previous DCE Studies}

To our knowledge, no previous DCE study has explicitly analyzed scope elasticity of WTP for attribute improvements. Nonetheless, many studies report estimation results from which it is possible to infer or extract such scope sensitivity measure. Here, we first examine a purposive sample of studies from the broader environmental economics literature (Table 1). ${ }^{7,8}$ Since our own DCE application presented in Sect. 4 and 5 are set in the intersection between environmental and energy economics, we also examine prior DCE studies specifically related to wind power preferences (Table 2). ${ }^{9}$ For each article, we identify the study context, which scope-relevant attributes were included in the DCE design, the functional form utilized in estimation, whether the article includes a discussion of the scope sensitivity issue, and the implied scope elasticities from its estimation results. ${ }^{10}$

\subsection{Examples From Environmental Economics}

Table 1 summarizes the review of ten articles from environmental economics. Only three of these include a scope discussion of the reported results (Layton and Brown 2000; Zhao et al. 2013; Badura et al. 2020). Four studies employ a restrictive functional form that imposes unitary scope elasticity (Adamowicz et al. 1994; Zhao et al. 2013; Meyerhoff et al. 2016; and Ando et al. 2020). One study (Adamowicz et al. 1998) estimates both linear and quadratic functional forms, whereas one study (Badura et al. 2020) utilizes linear specification for one quantitative attribute (size of recreation area) and logarithmic for another quantitative attribute (distance to recreation site). The remaining four articles employ piecewise linear functional form, i.e., dummy coding for different attribute levels. The estimation results reported in Boxall et al. (1996), Sandorf (2019), and Hynes et al. (2020) imply scope elasticities less than one, while the results in Layton and Brown (2000) suggest elastic WTP responsiveness.

Adamowicz et al. (1994), Boxall et al. (1996), and Adamowicz et al. (1998) comprise three highly cited early DCE applications in environmental valuation. Adamowicz et al. (1994) use DCE as supplement to the travel cost method to analyze choice of recreational fishing site, with expected fish catch being a key attribute of the study. The fish catch attribute is highly significant in estimation with $\bar{E}_{W T P}=1$ by imposed linear functional form.

\footnotetext{
7 The number of environmental DCE studies published the last 25 years is large. Therefore, we have not aimed for a complete, systematic review here. Instead, our selection represents an illustrative combination of pioneering applications and some of the most recently published work.

${ }^{8}$ We have intentionally chosen not to include any studies that explore preferences for health risk reductions and the value of statistical life. The role of scope is a central topic in these studies and specific theoretical priors have been developed in this literature (Goldberg and Roosen 2007; Lindhjem et al. 2011).

${ }^{9}$ Relevant studies were identified from the meta-analysis in Mattmann et al. (2016) and supplementary Google scholar searches.

${ }^{10}$ In order to identify whether the scope issue was addressed in this literature, we carefully read each article and digitally searched for relevant words or phrases (e.g., "scope", "size", "provision level, "internal validity", "construct validity", etc.) As a general rule, we report inferred scope elasticities based on the authors' explicitly or implicitly preferred model or the estimation deemed to be statistically superior. We restrict the extraction to computation of scope elasticity between the lowest and highest provision levels using the scope arc-elasticity formula in Eq. 5. Further details on how the reported scope elasticities were computed can be found in the supplementary material.
} 


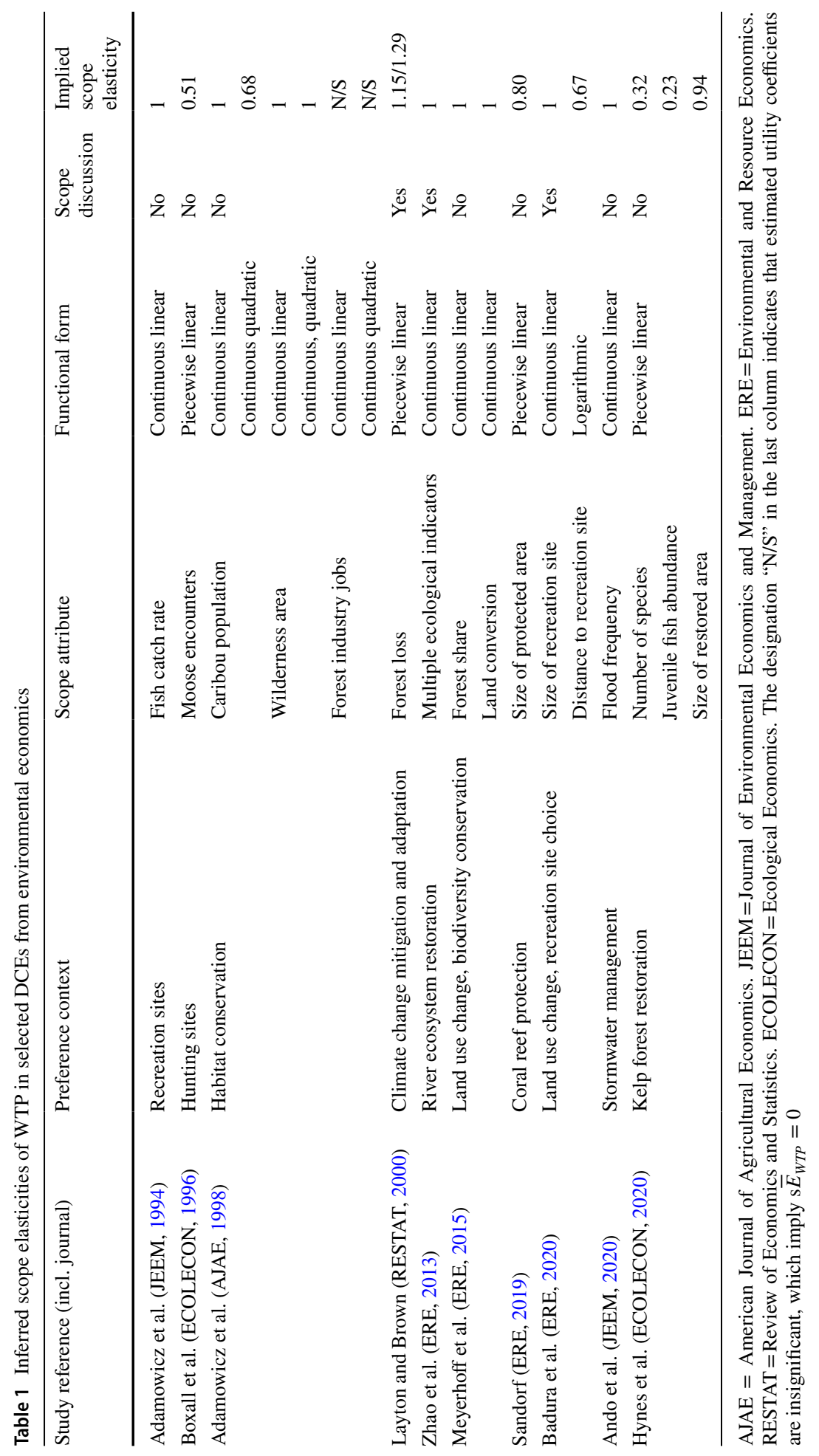


Boxall et al. (1996) compare DCE with CV methodology to study preferences for hunting sites. A main quantitative attribute is expected moose encounters. The implied scope elasticity of WTP for this attribute is 0.51 based on our extraction. Adamowicz et al. (1998) combine DCE and CV methodology to investigate non-use values associated with habitat conservation. The study has three quantitative attributes that lend themselves to scope analysis, namely, mountain caribou population, size of wilderness area, and number of forest industry jobs. ${ }^{11}$ In their quadratic model the implied scope elasticity of WTP for the caribou population is 0.68 . For the wilderness area attribute, the linear term is significant whereas the quadratic is not. This implies unitary scope elasticity for this attribute. The estimated linear and quadratic coefficients for the job attribute are insignificant, suggesting zero WTP and $\bar{E}_{W T P}=0$.

In two more recent studies on ecosystem service valuation, Sandorf (2019) reports welfare estimates for one attribute that lends itself to scope analysis (size of protected area) while Hynes et al. (2020) include three quantitative attributes (number of species, juvenile fish abundance, size of restored area). The inferred scope of elasticity of WTP is 0.8 in Sandorf (2019) and 0.32, 0.23, and 0.94, respectively, in Hynes et al. (2020).

Layton and Brown (2000) are the only authors to report welfare estimates that imply $\bar{E}_{W T P}>1$. The context of this study is preferences for avoiding adverse ecosystem impacts from climate change with a key attribute of interest being forest loss. The implied scope elasticity of WTP is 1.15 and 1.29 for a 60 -year and 150-year time horizon, respectively. These estimates are indicative of increasing marginal disutility from forest loss and increasing marginal WTP to avoid this climate change impact.

\subsection{Scope Elasticities in Wind Power DCE Studies}

Table 2 summarizes our review of 22 wind power related DCE studies. As can be seen from the third column, this literature has explored a wide range of non-monetary attributes related to the renewable energy mix, characteristics of wind power expansions, landscape, ecosystem, and air pollution effects, and economic impacts. Noteworthy, none of the studies explicitly discusses the scope sensitivity issue or carries out any internal validity diagnostics related to scope. ${ }^{12}$ Many of the attributes included in these studies preclude scrutiny of scope elasticity because they are described with categorical or qualitative representations (e.g., protection of cliffs, fauna, flora, and landscapes in Alvarez-Farizo and Hanley 2002). Furthermore, many of the quantitative attributes are entered linearly into estimation, which impose constant marginal utility and unitary scope elasticity of WTP (e.g., greenhouse gas emissions, electricity shortages, and jobs in Longo et al. 2008).

Piecewise linear specifications that permit testing for $\bar{E}_{W T P} \neq 1$ are utilized in ten of the 22 studies: Ladenburg and Dubgaard (2009), Drechsler et al. (2011), Landry et al. (2012), Westerberg et al. (2013), Vecchiato (2014), Börger et al. (2015), Brennan and Van Rensburg (2016, 2020), Dalton et al. (2020), and Peri et al. (2020). For example, Drechsler et al. (2011) explore four quantitative attributes (size of wind farm, maximum turbine height,

\footnotetext{
11 While our focus is scope in WTP for environmental attributes, for completeness, we also discuss and extract scope elasticities for other attributes included in the reviewed studies as well.

12 Longo et al. (2008) test for internal validity with respect to an expectation that WTP for attribute improvements is increasing in respondent income.
} 


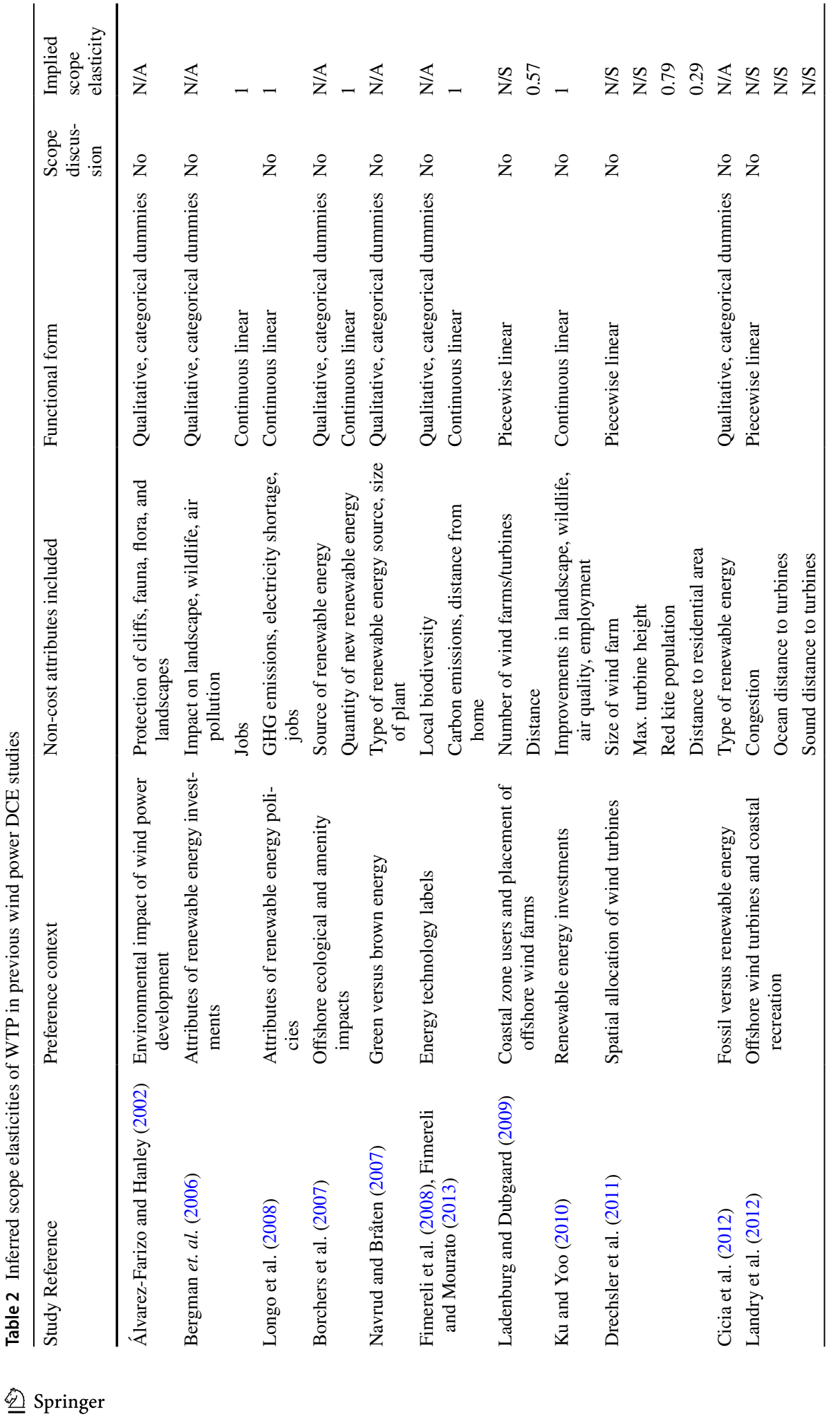




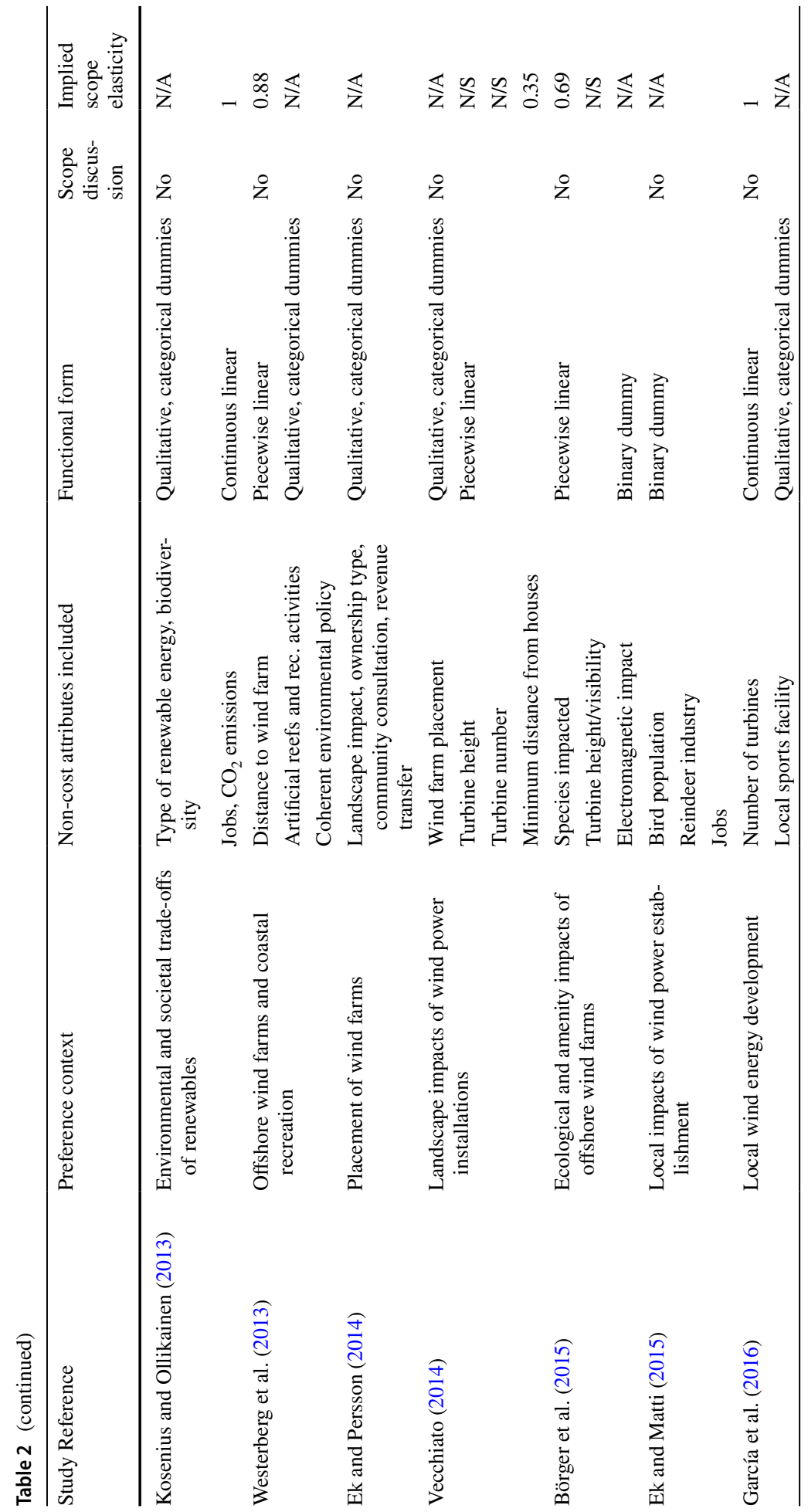




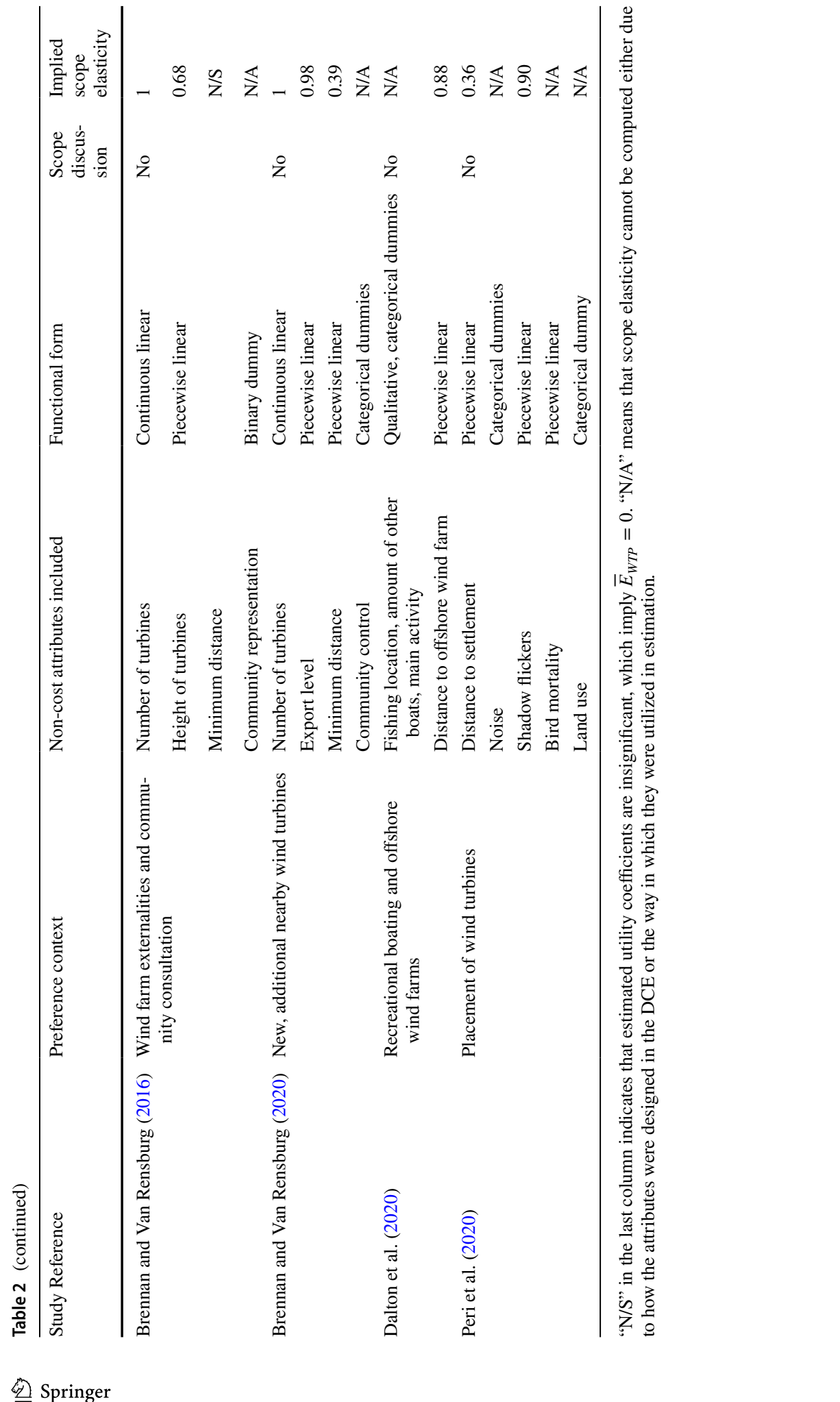


red kite population, minimum distance to residential areas). ${ }^{13}$ The first two attributes do not exhibit statistically significant scope effects, implying zero scope elasticity, while the inferred scope elasticity of WTP is 0.76 for red kites and 0.29 for minimum distance.

Several other studies also include an attribute related to spatial proximity. The inelastic scope sensitivity with respect to minimum distance in Drechsler et al. (2011) is consistent with the inferred scope elasticities of 0.57 in Ladenburg and Dubgaard (2009), 0.88 in Westerberg et al. (2013), 0.35 in Vecchiato (2014), 0.39 in Brennan and Van Rensburg (2020), 0.88 in Dalton et al. (2020), and 0.36 in Peri et al. (2020). In contrast, the distance attributes in Landry et al. (2012) and Brennan and Van Rensburg (2016) do not exhibit significant scope sensitivity.

The key quantitative wind power attribute in our application below is the number of new wind turbines to be built in Norway. Six out of the 22 studies reviewed in Table 2 include such turbine attribute. This attribute is significant, with restricted unitary scope elasticity in Brennan and Van Rensburg (2016), Garcia et al. (2016), and Brennan and Van Rensburg (2020). In contrast, the turbine attribute is insignificant in Ladenburg and Dubgaard (2009) and Vecchiato (2014), and almost perfectly correlated with the statistically insignificant wind farm size attribute in Drechsler et al. (2011). Overall, this brief review reveals a general lack of attention to scope effects in the DCE literature to date.

\section{Empirical Application}

We analyze data from a recent DCE study of preferences relating to expansion of renewable energy production in Norway which had a specific focus on wind power externalities. The study was motivated by the Norwegian Government's 2018 call for a long-term national plan for the expansion of wind power production on land. The Ministry of Petroleum and Energy assigned the Norwegian Water Resources and Energy Directorate (NVE) the tasks of providing an update of the scientific knowledge base and identifying the geographical areas of Norway that would be the most suitable for new wind farms.

The interest in expanding wind power production has two primary policy motivations. First, even though Norway is self-sufficient regarding renewable electricity, less than $2 / 3$ of domestic energy consumption is met from renewable sources. ${ }^{14}$ Second, the Norwegian Government wants to expand renewable production to meet international commitments towards transforming the global energy system and reducing carbon emissions. In 2018, the wind power industry generated 3-4 TWh per year on 30 sites with 610 wind turbines. An additional 30 projects with 600-700 new turbines had also been approved and were under planning or construction. With some of Europe's best wind resources, the Government envisages that wind power production could reach 25 TWh per year by 2030, depending on production costs and prospective electricity prices (NVE 2019).

NVE's work on the national plan started with the mapping of 43 areas distributed across different regions of Norway that were deemed to have high potential and meet basic

\footnotetext{
13 Data from the same underlying DCE study is also utilized in Meyerhoff et al. (2010) and Mariel et al. (2015).

14 In a typical year, Norway is a net exporter of renewable electricity, with a production portfolio comprising $95 \%$ hydropower and 5\% thermal and wind power. For more information, see the following electricity and energy reports from Statistics Norway: www.ssb.no/energi-og-industri/statistikker/elektrisitet/aar and www.ssb.no/energi-og-industri/statistikker/energibalanse.
} 
eligibility criteria for new wind power deployment. NVE then examined each of these areas with respect to production and transmission capacity, stakeholder interests, and environmental impact. During this work, NVE commissioned multiple technical/scientific reports from external consultants, collaborated with the Norwegian Environment Agency, and solicited input from local and regional stakeholders in both the private and the public sector. This process led to the identification of a sub-set of 13 geographical areas proposed for future prioritization. The priority areas are located throughout Norway, with concentrations in Central and Western Norway, and comprise mostly coastal and mountain landscapes.

Despite the deliberate planning process, the final report (NVE 2019) met widespread criticism leading to intense debate in social and public media. Citizens expressed concern about the impact of wind power installations on Norway's increasingly reduced pristine nature. Various environmental groups and outdoor recreation and tourism organizations protested. Local politicians objected on the basis that the plan would limit their local autonomy. Finally, the wind power industry itself opposed the plan because of the spatial constraints it placed on future expansions of production. Our study was conducted concurrently with NVEs planning process. Hence, we argue that our DCE study exhibits an unusually high degree of policy relevance and consequentiality.

Broadly speaking, consequentiality refers to ensuring that respondents believe that their responses to and overall results of the DCE could influence policy decisions with real monetary and public good-provision implications for them (Johnston et al. 2017). In addition to its timing, our DCE survey had many design elements to enhance consequentiality, including carefully explained attributes, realistic policy scenarios, and a credible payment vehicle. Furthermore, the information treatment leading up to the DCE choice tasks was carefully framed around the Government's plan, the coordinating planning agency (NVE), and facts and figures from several scientific reports published prior to the plan's release. ${ }^{15}$ Next, we describe the features of our DCE design most central to the subsequent scope elasticity analysis in Sect. $5 .^{16}$

\subsection{The DCE Design}

The DCE survey was designed over a 15-month period starting in January 2018, with implementation in April 2019. An overarching design consideration was the objective of making the study relevant for national policy decisions. The selection and configuration of attributes and other elements of the choice architecture was the combined outcome of a careful review of the existing literature, input from a workshop with experts on valuation of wind power externalities, and feedback from two focus groups and several pilot tests, and following general SP guidance (e.g., Hoyos 2010; Johnston et al. 2017).

The final survey started with questions that elicited general opinions, awareness, and knowledge before guiding the respondents through information about Norway's renewable energy production and potential plans for future expansions. Next, the respondents were

\footnotetext{
15 The survey also included the following explicit statement (translated from Norwegian) to boost consequentiality: "This survey is carried out by researchers at several Norwegian research institutions, including Statistics Norway and University of Stavanger, and deals with the production of wind power in Norway. The results from the survey will be part of the authorities' information basis for decisions on future wind power licenses, both in terms of the desired scope, pace of development, and geographical location. Your opinions are therefore very important to these decisions."

${ }^{16}$ Dugstad et al. (2020) provide further details. A translated version of the DCE part of the survey is available as supplementary material.
} 
provided details on the structure of the DCE, including careful descriptions of alternatives and attributes. At the core of the DCE, the respondents were asked to express their preferences on a series of choice cards. Standard debriefing, attitudinal, and socio-economic questions followed at the end of the survey.

Figure 1 provides an illustrative choice card. Each choice card contained three alternatives, status quo and two scenarios with expansion of energy production, varying in five attributes. The first attribute, new renewable energy production from all sources, had experimental levels of zero (no change), 10, 20, and $30 \mathrm{TWh}$ per year. The second attribute, new wind turbines, had experimental levels of zero (no change), 600, 1200, and 3000 turbines. The third attribute designated prioritized region for new wind power production (no prioritization, Northern Norway and Central Norway, Western Norway, or Eastern Norway and Southern Norway). The fourth attribute was prioritized landscape type for new wind power production (no prioritization, coastal land, lowland and forest land, or mountain land). Finally, the fifth attribute, change in household's monthly electricity bill (NOK), had experimental levels of $-450,-150$, zero (no change) +150 , and $+450 .{ }^{17}$ We used the \%ChoicEf and \%MktBlock macros in the software SAS® along with the procedures described in Kuhfeld (2010) to generate the DCE design, with constraints imposed to avoid meaningless or unrealistic combinations of attribute levels. ${ }^{18,19}$ Specifically, a total of 24 choice sets were generated and divided into three blocks. Each survey participant was randomized into one block, thereby receiving eight choice tasks. The D-efficiency for the DCE design was 0.89 .

The two quantitative non-cost attributes are of particular interest for the scope elasticity analysis in this paper. The first attribute is intended to broadly capture the nonmarket benefits of expanding Norway's production of renewable energy. Both prior research and our focus group results indicate that people are positive to such expansion for reasons related to concern over energy security, support of greenhouse gas emission reduction, and a desire to stimulate economic activity. The second attribute is intended to capture specific preferences for wind power, holding constant the level of renewable energy production. As documented by prior research summarized in Mattman et al. (2016) and Zerrahn (2017), wind turbines and accompanying infrastructure (e.g., roads and power lines) have multiple adverse impacts. These impacts include habitat displacement, ecosystem fragmentation, negative effects on recreational experiences and visual landscape amenities, and issues related to noise and light-, shadow- and ice-casting. In total, these externalities can reduce the well-being of local residents (e.g., Gibbons 2015; Krekel and Zerrahn 2017), lower the growth potential of other regional industries such as tourism and recreation (e.g., Brökel and Alfken 2015), and generally threaten non-use values associated with the protection of pristine nature (Krutilla 1967).

\footnotetext{
17 Electricity prices in Norway are affected by a number of demand and supply factors. Hence, the electricity prices faced by Norwegian households can credibly go up or down (regardless of the extent of wind power expansion). Therefore, the cost attribute included both reductions and increases in the electricity bill. Pre-testing indicated that this was an important design feature for avoiding scenario rejections and protest responses. The cost attribute was carefully explained in the information treatment leading up to the choice tasks.

$18 \mathrm{http} / / /$ support.sas.com/techsup/technote/mr2010choiceff.pdf.

19 http://support.sas.com/techsup/technote/mr2010mktblock.pdf.
} 


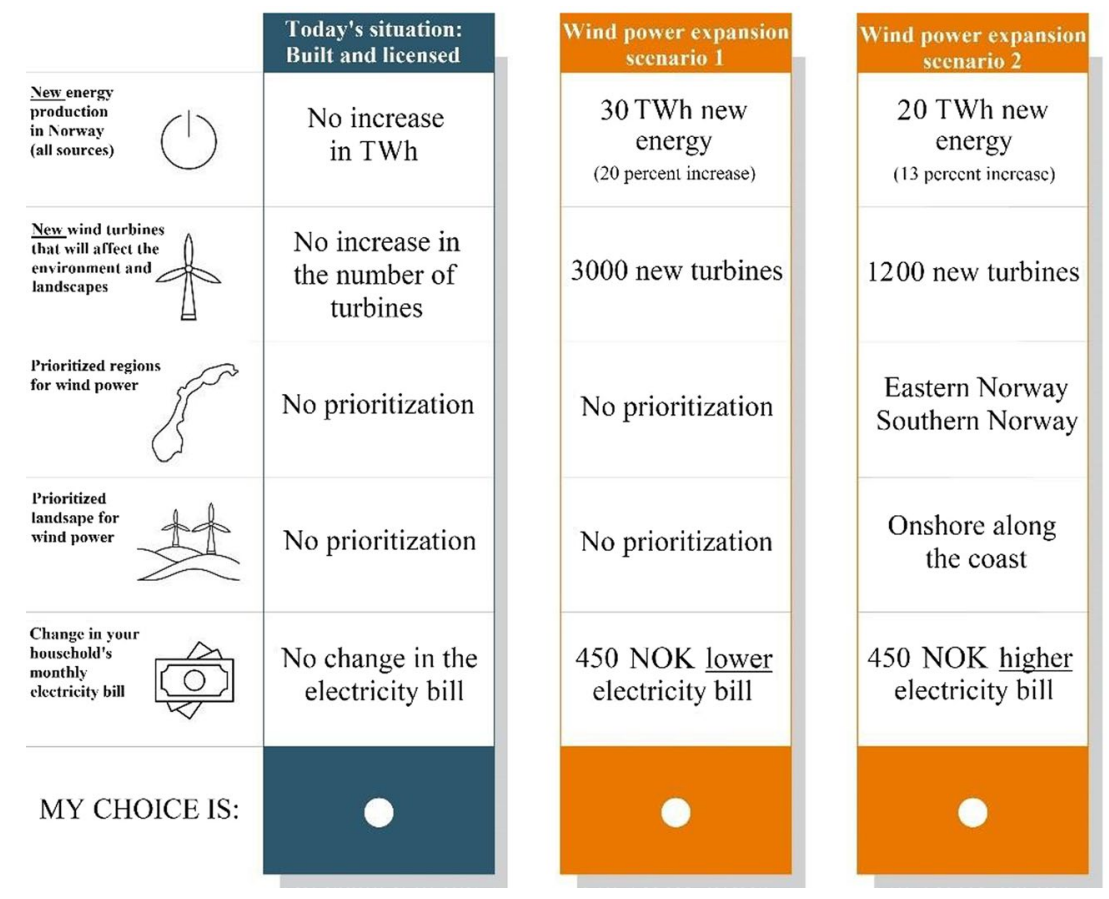

Fig. 1 Sample choice card (wind turbine version, translated from Norwegian)

\subsection{Sampling Scheme, Experimental Design Variation and Implementation}

During the survey development stages, previous experience and the likelihood of future exposure were identified as potentially important determinants of preferences. For this reason, it was decided to conduct the survey in two geographic regions with differential experiences and exposure. Specifically, we sampled Rogaland County in Western Norway and Oslo County in Eastern Norway with population sizes (shares) of approximately 476000 (9\%) and 681000 (13\%), respectively. Rogaland is the county that currently has most wind power production and could have substantially more in the future. In contrast, Oslo does not have wind power production and is also unlikely to have any in the future.

In our analysis, we investigate potential differences in scope elasticities across the two subsamples. The tentative a priori expectation is that wind power experience/exposure could affect both WTP and scope elasticity estimates. Previous research indicates that WTP to avoid adverse impacts from industrial development may be higher or lower as result of experience/exposure, depending on the mechanisms at play (Zerrahn 2017; Dugstad et al. 2020). However, this research is silent with respect to how experience/exposure might affect scope sensitivity. Consequently, we do not hypothesize a specific sign on expected difference in scope elasticities between the two counties.

In addition to the dual-region sampling scheme, we also implement experimental variation in the unit of measurement of the wind power attribute. Half the respondents were given choice cards with new wind turbines (as in Fig. 1), while the other half received cards with new production sites. The two survey versions were otherwise identical. These two measurement units were 
perfectly correlated ( 1 production site $=30$ wind turbines; 30 wind turbines $=1$ production site). This implies identical wind power production, land capture, and environmental impacts across the experimental versions. The motivation for this experimental treatment is an emerging literature on attribute translations, choice architecture, and signposting/nudging (e.g., Hertwig and Grüne-Yanoff 2017; Ungemach et al. 2018), which suggests that how an attribute is presented in a choice context, including its unit of measurement, is not arbitrary. Specifically, different measurement units can invoke different motivational associations or activate different objectives/goals (e.g., Dellaert et al. 2018; Schlüter et al. 2017). Consequently, the representation of an attribute may cause people to weight the attribute differently in the decision-making process. A change in unit of measurement could also potentially shift the weight of the attribute in question relative to other choice dimensions. Here, we investigate whether a seemingly innocuous change in unit of measurement, from number of wind turbines to number of production sites, alters scope elasticity estimates. This is particularly interesting since elasticities are unit free. In our split-sample DCE, a one percent increase in number of wind turbines is the same as a one percent increase in number of production sites. Hence, our tentative a priori expectation is that unit of measurement will not have an impact on scope elasticity estimates.

The data collection was implemented as an online survey using the pre-recruited internet panel of NORSTAT, ${ }^{20}$ one of the leading survey companies in Norway. In total, 4404 individuals were invited to participate in the survey. The topic of the survey was not revealed in the survey invitation. The response rate was $24 \%$ and the dropout rate was $12 \%$. Table 8 in the appendix provides basic descriptive statistics for the full dataset, the geographic subsamples, and the unit of measurement subsamples.

\section{Empirical Analysis}

The stated preferences in our DCE are motivated from a standard RUM framework with $U_{n j t}=V_{n j t}+\varepsilon_{n j t}$, where $U_{n j t}$ represents total indirect utility, $V_{n j t}$ is deterministic utility, and $\varepsilon_{n j t}$ is stochastic utility for respondent $n$ associated with alternative $j$ in choice occasion $t$. The underlying assumption of the RUM framework is that preference expressions are consistent with utility maximization such that alternative $i$ is chosen by individual $n$ in choice occasion $t$ if and only if $U_{n i t}>U_{n j t}$. The goal of the data analysis is to estimate deterministic utility as a function of observable attributes $\left(\boldsymbol{x}_{n j t}\right)$ and unknown preference weights or parameters $\left(\boldsymbol{\beta}_{n}\right)$, in general, $V_{n j t}=V_{n j t}\left(\boldsymbol{x}_{n j t}, \boldsymbol{\beta}_{n}\right)$. The most common econometric approach is to use panel mixed logit techniques (Hensher et al. 2005; Train 2009). If we let $\boldsymbol{i}_{n}$ represent the sequence of preference expressions made by respondent $n$ over $J$ alternatives in $T$ choice occasions, then the joint panel mixed logit probability is given by:

$$
\operatorname{Prob}\left(\boldsymbol{i}_{n} \mid \boldsymbol{\theta}\right)=\int \prod_{t=1}^{T} \frac{\exp \left(V_{\text {int }}\right)}{\sum_{j}^{J} \exp \left(V_{j n t}\right)} f\left(\boldsymbol{\beta}_{n} \mid \boldsymbol{\theta}\right) d \boldsymbol{\beta}_{n}
$$

where $f\left(\boldsymbol{\beta}_{n} \mid \boldsymbol{\theta}\right)$ represents a distribution function for the unknown preference parameters $\left(\boldsymbol{\beta}_{n}\right)$ described by a set of coefficients $(\boldsymbol{\theta})$, typically central tendencies, variances, and

20 www.norstat.no. 
Table 3 Variables used in the estimation of deterministic indirect utility

\begin{tabular}{ll}
\hline Name & Description \\
\hline COST & Change in household monthly electricity price \\
TWH & New renewable energy production in Norway, TWh (per year) \\
TWH2 & Squared term for TWH \\
TURB & Number of new wind turbines built in Norway \\
TURB2 & Squared term for TURB \\
TWH10 & Dummy for 10 TWh of new renewable energy production in Norway (per year) \\
TWH20 & Dummy for 20 TWh of new renewable energy production in Norway (per year) \\
TWH30 & Dummy for 30 TWh of new renewable energy production in Norway (per year) \\
TURB600 & Dummy for 600 new wind turbines built in Norway \\
TURB1200 & Dummy for 1200 new wind turbines built in Norway \\
TURB3000 & Dummy for 3000 new wind turbines built in Norway \\
MOUNT & Dummy for mountain landscapes being prioritized for new wind power \\
LOW & Dummy for lowland and forest landscapes being prioritized for new wind power \\
COAST & Dummy for coastal landscapes being prioritized for new wind power \\
NORTHMID & Dummy for prioritizing Northern and Central Norway for new wind power \\
WEST & Dummy for prioritizing Western Norway for new wind power \\
EASTSOUTH & Dummy for prioritizing Eastern and Southern Norway for new wind power \\
\hline
\end{tabular}

covariances, to be estimated. This probability expression lacks a closed-form solution and must instead be simulated. ${ }^{21}$

In our application, we specify a multivariate normal distribution for the preference parameters on non-cost attributes in order to account for multiple observations per respondent and preference heterogeneity. The normality assumption is flexible in the sense that it supports both positive and negative preferences, which is appropriate in our case. For example, many respondents will associate new wind turbines with disutility due to negative environmental impacts, while others may perceive them as generating a net good. Furthermore, the joint nature of the distribution permits preference weights for specific attributes or attribute levels to be correlated. For example, it seems reasonable to believe that high disutility (or utility) from one level of wind power expansion (e.g., 600 new turbines) is positively correlated with preferences for another level of expansion (e.g., 3000 new turbines).

Below we report results from three different specifications of deterministic indirect utility $\left(V_{n j t}\right)$. For convenience, the variable names and descriptions are provided in Table 3. The first specification (LINEAR) is restrictive and only included for comparison purpose. It imposes constant marginal utilities and scope elasticity of one for new renewable energy production and wind turbines. The second specification (QUADRATIC) brings more flexibility by adding squared terms for these two attributes. The third specification

\footnotetext{
21 We omit full exposition of the panel mixed logit model and its simulation procedures for brevity and instead refer the reader to any one of a number of textbooks (e.g., Hensher et al. 2005; Train 2009). The estimation results presented in this paper were produced in the Apollo package for the $R$-software and are stable across a series of technical robustness tests (e.g., variation in the number and types of random draws etc.).
} 
(PIECEWISE) enters the levels of these two attributes with separate indicators (i.e., dummy variables), which arguably provides the highest degree of functional form flexibility (Layton and Brown 2000). Deterministic utility for this specification can be written out as follows:

$$
\begin{aligned}
& V_{n j t}=\alpha_{S Q}+\beta_{1} \operatorname{COST}_{i t}+\beta_{2, n} T W H 10_{n j t}+\beta_{3, n} T W H 20_{n j t}+\beta_{4, n} T W H 30_{n j t}+ \\
& \beta_{5, n} \text { TURB } 600_{n j t}+\beta_{6, n} \text { TURB } 1200_{n j t}+\beta_{7, n} \text { TURB } 3000_{n j t}+\beta_{8, n} \text { MOUNT }{ }_{n j t}+ \\
& \beta_{9, n} L O W_{n j t}+\beta_{10, n} \text { COAST }_{n j t}+\beta_{11, n} \text { NORTHMID }_{n j t}+\beta_{12, n} \text { WEST }_{n j t}+\beta_{13, n} \text { EASTSOUTH }_{n j t}
\end{aligned}
$$

The variable COST represents change in the household's monthly electricity bill, while the variables $T W H 10, T W H 20$, and TWH3O are indicators for the levels of new renewable energy production and TURB600, TURB1200, and TURB3000 are indicators for numbers of new wind turbines. The remaining variables (NORTHMID, WEST, EASTSOUTH, MOUNT, LOW and COAST) are indicators for regional and landscape prioritizations. The parameter on the COST attribute $\left(\beta_{1}\right)$ identifies marginal utility of money and is essential for deriving monetary values associated with changes in the level of non-cost attributes. For example, respondent $n$ 's implied WTP for $10 \mathrm{TWh}$ new renewable energy production is given by the expression $-\beta_{2, n} / \beta_{1}$ Similarly, individual $n$ 's incremental WTP for avoiding 3000 instead of 600 new wind turbines is given by the expression $\left(\beta_{7, n}-\beta_{5, n}\right) / \beta_{1}{ }^{22,23}$

\subsection{Baseline Results and Comparison Across Functional Forms}

Estimation results for the full dataset are reported in Table 4. Overall, the three model specifications yield consistent patterns for key utility parameters. The estimated COST parameter is negative and highly significant, as expected. The average respondent obtains positive utility from expansion of renewable energy production and disutility from increasing the number of turbines, as indicated by the signs of the mean coefficients of the linear terms (TWH and TURB). The signs of the coefficients of the quadratic terms (THW2 and TURB2) in the QUADRATIC model indicate diminishing marginal utility from new renewable energy production and diminishing marginal disutility from new wind turbines. These preference patterns are also reflected in the PIECEWISE estimation. For example, the difference between the mean coefficients of TURB600 and TURB1200 is larger than the difference between the mean coefficients of TURB1200 and TURB3000. The results for the indicators of prioritized regions and landscapes, which are of second-order interest

\footnotetext{
22 The cost parameter is specified as fixed for easier interpretation of welfare estimates (Revelt and Train 1998; Holmes et al. 2017) and to avoid the need for utility-theoretic restriction on a random parameter (e.g., lognormal marginal utility of money), which could lead to convergence issues or implausibly high welfare estimates (Holmes et al. 2017). Specifying some parameters as fixed has also been found to facilitate overall model identification (Ruud 1996; Revelt and Train 1998). In our case, $\beta_{1}$ can be interpreted as the average preference weight on the COST attribute and the implied WTP distribution for non-cost attribute improvements follows from the normality of the non-cost parameters. We relax this assumption in a robustness check reported in Sect. 5.4.

${ }^{23}$ We recognize that estimation of RUM models in so-called WTP space (Train and Weeks 2005) have become more common of late and are conceptually appealing given our focus on scope effects in welfare estimates. Nonetheless, we report models estimated in preference space as our main results since the majority of past DCE studies (including those that we reviewed in Sect. 3) have used this approach. We provide a robustness check against models estimated in WTP space in Sect. 5.4.
} 
Table 4 Full sample panel mixed logit parameter estimates for different functional forms of deterministic indirect utility (linear, quadratic, and piecewise linear)s

\begin{tabular}{|c|c|c|c|c|c|c|}
\hline \multirow{2}{*}{$\begin{array}{l}\text { Model } \\
\text { Attribute }\end{array}$} & \multicolumn{2}{|l|}{ Linear } & \multicolumn{2}{|l|}{ Quadratic } & \multicolumn{2}{|l|}{ Piecewise } \\
\hline & Mean & SD & Mean & SD & Mean & SD \\
\hline ASC & 0.0597 & & $0.1029^{*}$ & & $0.1124 * *$ & \\
\hline COST & $-0.0036^{* * *}$ & & $-0.0038 * * *$ & & $-0.0040 * * *$ & \\
\hline TWH & $0.0257 * * *$ & $0.0731 * * *$ & $0.0883 * * *$ & $0.1605^{* * *} *$ & & \\
\hline TWH2 & & & $-0.0019 * * *$ & -0.0001 & & \\
\hline TURB & $-0.0003^{* * *}$ & $0.0009 * * *$ & $-1.4587 * * *$ & $3.7849 * * *$ & & \\
\hline TURB2 & & & $0.3388 * * *$ & $0.1865^{* * *}$ & & \\
\hline TWH10 & & & & & $0.8703 * * *$ & 0.3272 \\
\hline TWH20 & & & & & $1.0315 * * *$ & $0.7732 * * *$ \\
\hline TWH30 & & & & & $1.1447 * * *$ & 0.0327 \\
\hline TURB600 & & & & & $-1.0198 * * *$ & $2.2969 * * *$ \\
\hline TURB1200 & & & & & $-1.4412 * * *$ & $0.3479 * *$ \\
\hline TURB3000 & & & & & $-1.4867 * * *$ & $1.5380 * * *$ \\
\hline MOUNT & $-0.5888 * * *$ & $1.7645^{* * *} *$ & 0.1161 & $1.3091 * * *$ & 0.2373 & 0.5140 \\
\hline LOW & $-0.5440 * * *$ & $1.1199 * * *$ & 0.1466 & 0.3122 & 0.2259 & $0.7067 * * *$ \\
\hline COAST & $-0.4527 * * *$ & $0.8867 * * *$ & 0.1369 & $0.4872 * * *$ & 0.2384 & $0.4734^{* *}$ \\
\hline NORTHMID & -0.0819 & $0.6808^{* * *} *$ & -0.2882 & $0.4613 * * *$ & $-0.3776^{* *}$ & 0.0994 \\
\hline WEST & $-0.3020 * *$ & $1.2120 * * *$ & $-0.5044 * * *$ & $0.4128 * * *$ & $-0.5111 * * *$ & $0.4722 * *$ \\
\hline EASTSOUTH & -0.0297 & 0.1114 & -0.2558 & $0.1972 * * *$ & $-0.3609 *$ & 0.4777 \\
\hline Log likelihood & -5341.717 & -5227.6 & -5184.928 & & & \\
\hline AIC & $10,775.43$ & $10,590.72$ & $10,553.86$ & & & \\
\hline $\mathrm{BIC}$ & $11,087.77$ & $11,045.65$ & $11,178.53$ & & & \\
\hline Pseudo- $\mathrm{R}^{2}$ & 0.2597 & 0.2760 & 0.2814 & & & \\
\hline No. of obs & 6568 & 6568 & 6568 & & & \\
\hline
\end{tabular}

Note: $* * * p<0.01, * * p<0.05, * p<0.1$. Random parameter covariances are excluded for brevity. Table 9 in the appendix reports the estimated correlation matrix from the PIECEWISE model. The turbine attribute in QUADRATIC was scaled by 1000 to facilitate convergence

for the research focus of this article, are mixed. ${ }^{24}$ The estimated standard deviation coefficients are generally large and significant, suggesting substantial preference heterogeneity. Lastly, the overall goodness-of-fit statistics (pseudo-R ${ }^{2}$, AIK, and BIC) indicate that the PIECEWISE model is statistically superior. ${ }^{25}$

Figure 2 illustrates the estimated scope effects by providing empirical scope lines, which are linear interpolations of welfare estimates across the experimental attribute levels (Lopes and Kipperberg 2020). Specifically, the figure provides scope lines for the

\footnotetext{
${ }^{24}$ Note that these indicators serve as important ceteris paribus controls in estimation of utility parameters for the attributes of new renewable energy production and new wind turbines, and the subsequent analysis of welfare effects and scope elasticities.

${ }^{25}$ For brevity, we have not included covariances for the random parameters (specified as multivariate normally distributed) in Table 4. The estimated correlation matrix for the PIECEWISE model is available in the appendix (Table 9).
} 
Turbines
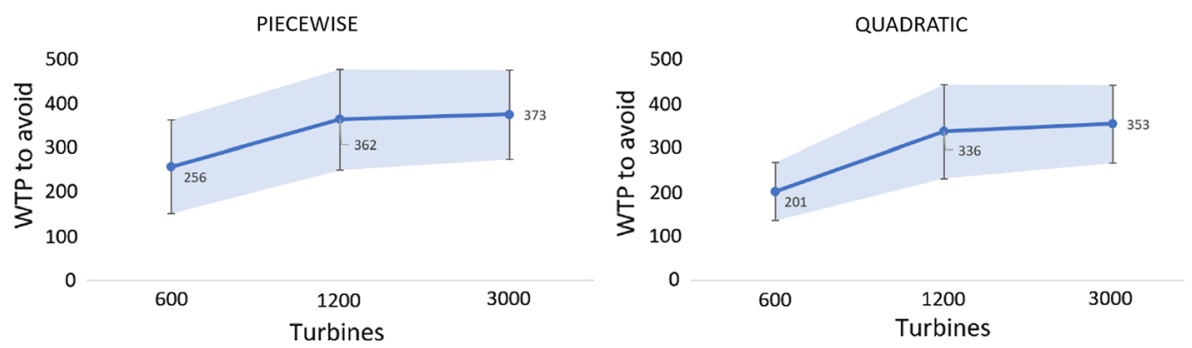

Renewable Energy

PIECEWISE

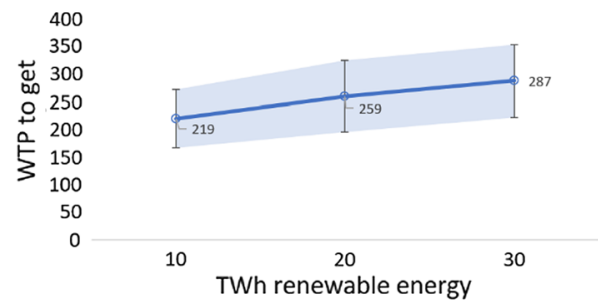

QUADRATIC

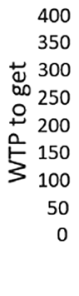

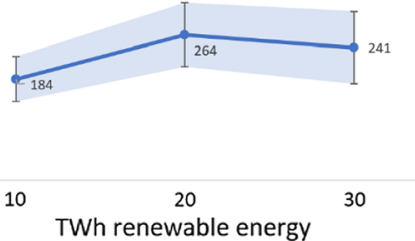

Fig. 2 Empirical Scope lines-Full sample WTP per household per month (mean and 95\% CI) for PIECEWISE and QUADRATIC for attributes TURB (number of turbines) and TWH (renewable electricity production in TWh). Note: Confidence intervals are computed by the Krinsky \& Robb method (1986)

PIECEWISE and QUADRATIC models based on the estimated mean WTP for 10, 20, and $30 \mathrm{TWh}$ of new renewable energy production and the estimated mean WTP to avoid 600, 1200, and 3000 new wind turbines, respectively. The numbers are in Norwegian kroner (NOK) on a per household per month basis. ${ }^{26}$

Table 5 offers a full statistical analysis of the welfare estimates (WTPs) from all three models and estimated scope elasticities $\left(\hat{E}_{W T P}\right)$ between the lowest and highest attribute levels. As can be seen, the LINEAR model has the lowest welfare estimates, which increase monotonically due to the constant marginal utility restriction. The QUADRATIC and PIECEWISE specifications generate somewhat higher WTP estimates. For example, the estimated mean WTP to avoid 600, 1200 and 3000 turbines are NOK 41, 82, and 205 in the LINEAR model versus NOK 256, NOK 362, and NOK 373 in the PIECEWISE model.

The estimated utility coefficients in Table 4 together with the corresponding welfare measures in Fig. 2 and Table 5 establish the presence of scope sensitivity. In general, the welfare measures for higher attribute levels are greater than those for lower levels. Furthermore, the estimated scope effects are statistically significant. For the LINEAR model, statistical significance follows directly from the significance of the estimated mean coefficients of THW and TURB. In the QUADRATIC and PIECEWISE cases, statistical scope significance is indicated by fact that the differences in WTP estimates for the highest versus the lowest attribute levels are statistically greater than zero. For example, the simulated

\footnotetext{
${ }^{26}$ Given the specific nature of our DCE design, reported welfare estimates for the wind power attribute can be interpreted either as WTP to avoid new wind turbines or WTA compensation for new wind turbines.
} 


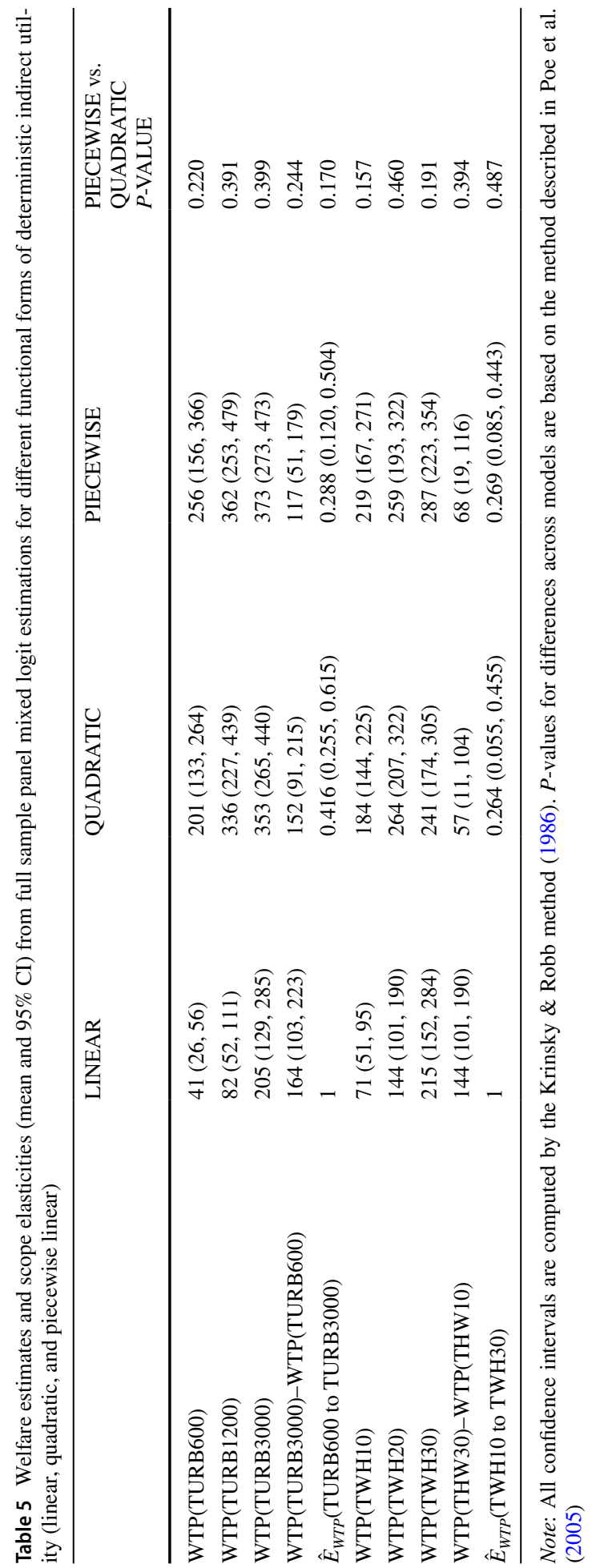


difference in mean WTP to avoid 3000 vs. 600 new wind turbines is NOK 117 in the PIECEWISE model. The $95 \%$ confidence interval for this difference has a lower bound of NOK 51 and an upper bound of NOK 179.

With regard to the estimated scope elasticities, the LINEAR model imposes unitary elastic scope sensitivities. Hence, $\hat{E}_{W T P}=1$ for both attributes. In the QUADRATIC and PIECEWISE models, $\hat{E}_{W T P}$ for avoiding new wind turbines evaluated from 600 to 3000 wind turbines is 0.416 and 0.288 , respectively. Similarly, $\hat{E}_{W T P}$ for new renewable energy production evaluated between 10 and 30 TWh is 0.264 in the QUADRATIC model and 0.269 in the PIECEWISE model. The confidence intervals around these estimates indicate that both elasticities are statistically greater than zero and less than one, i.e., suggesting inelastic responsiveness in WTP. Combined, these results suggest that the functional form of deterministic indirect utility may influence scope inference in DCE studies. Below, we investigate the data further at the subsample-level using the PIECEWISE specification. Results are reported in Figs. 3 and 4 and Tables 6 and 7.

\subsection{Comparison Across Geographic Subsamples}

The patterns of estimated utility parameters in terms of signs, significances, and relative magnitudes from the geographic subsample estimations (Table 6) are similar to those for the full sample estimation (Table 4). Furthermore, all empirical scope lines in Fig. 3 are upward sloping, suggesting presence of scope effects in both subsamples. However,

\section{Turbines}
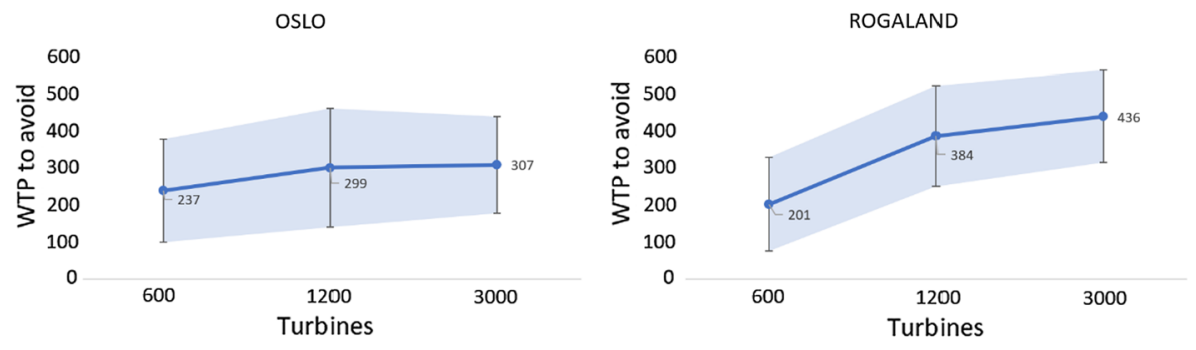

Renewable energy
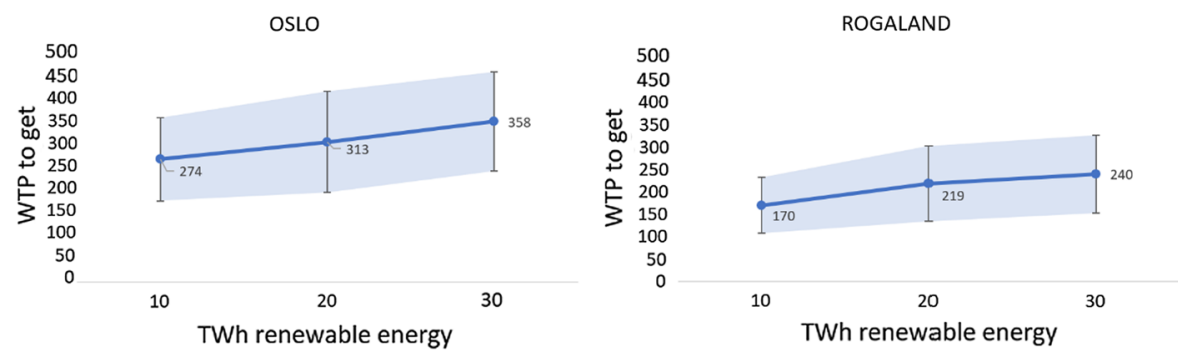

Fig. 3 Empirical Scope lines-WTP per household per month (mean and 95\% CI) by geographic subsample (Oslo and Rogaland counties) for the attributes TURB (number of turbines) and TWH (renewable electricity production in TWh) based on piecewise linear specification. Note: Confidence intervals are computed by the Krinsky \& Robb method (1986) 


\section{Turbines/Sites}
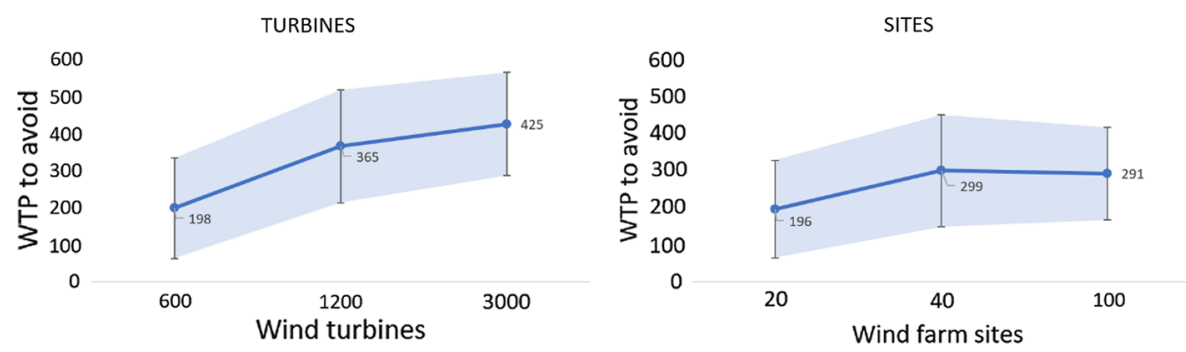

Renewable energy
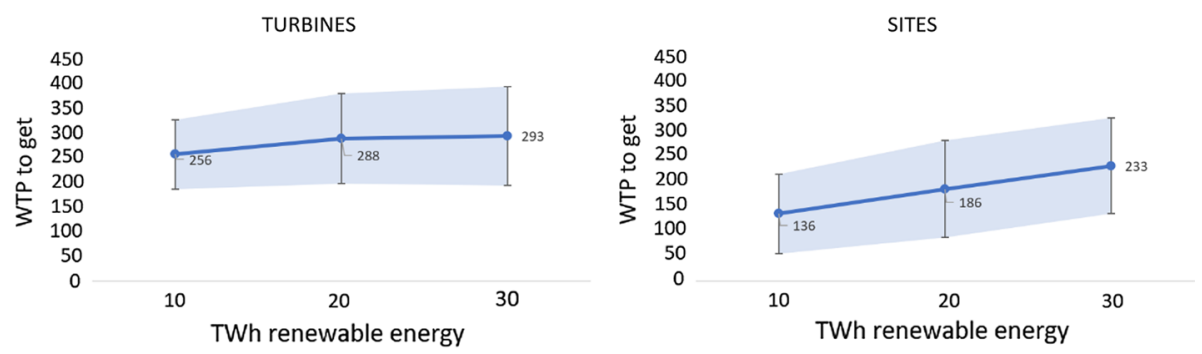

Fig. 4 Empirical Scope lines-WTP per household per month (mean and 95\% CI) by unit of measurement subsample (1 site $=30$ turbines) for the attributes TURB (no. of turbines) and TWH (renewable electricity production in TWh) based on piecewise linear specification. Note: Confidence intervals are computed by the Krinsky \& Robb method (1986)

the scope lines for ROGALAND appear steeper than those for OSLO by visual inspection, especially when it comes to the wind turbine attribute. This observation is supported by the estimated welfare effects and scope elasticities summarized in Table 7. The estimated difference in WTP to avoid 3000 vs. 600 wind turbines in the ROGALAND model $(436-201=$ NOK 235$)$ is higher than in the OSLO model $(307-237=$ NOK 70$)$. Correspondingly, $\hat{E}_{W T P}$ is 0.576 for the ROGALAND subsample versus 0.216 for the OSLO subsample. This subsample difference in scope elasticity is statistically significant at a $10 \%$ level $(P$-value $=0.077)$ by the full combinatorial convolution method suggested by Poe et al. (2005), see the third numeric column of Table 7. In combination, the higher WTPs and scope sensitivity associated with the turbine attribute in the Rogaland subsample suggest that experience and exposure may adversely affect wind power acceptance in Norway. ${ }^{27}$ When it comes to scope elasticity of WTP for new renewable energy production, $\hat{E}_{W T P}$ between 10 and $30 \mathrm{TWh}$ is slightly higher in the ROGALAND model (0.346) than in the OSLO model (0.268). However, the difference is not statistically significant $(P$-value $=0.347)$.

\footnotetext{
27 These differences could be attributable to factors other than experience and exposure (Dugstad et al. 2020). For example, the two geographic subsamples have slightly different socioeconomic profiles, see appendix (Table 8). However, a robustness check in Dugstad et al. (2020) using propensity score matching techniques (Liebe et al. 2015) retained the subsamples differences in welfare estimated and implied scope elasticities.
} 


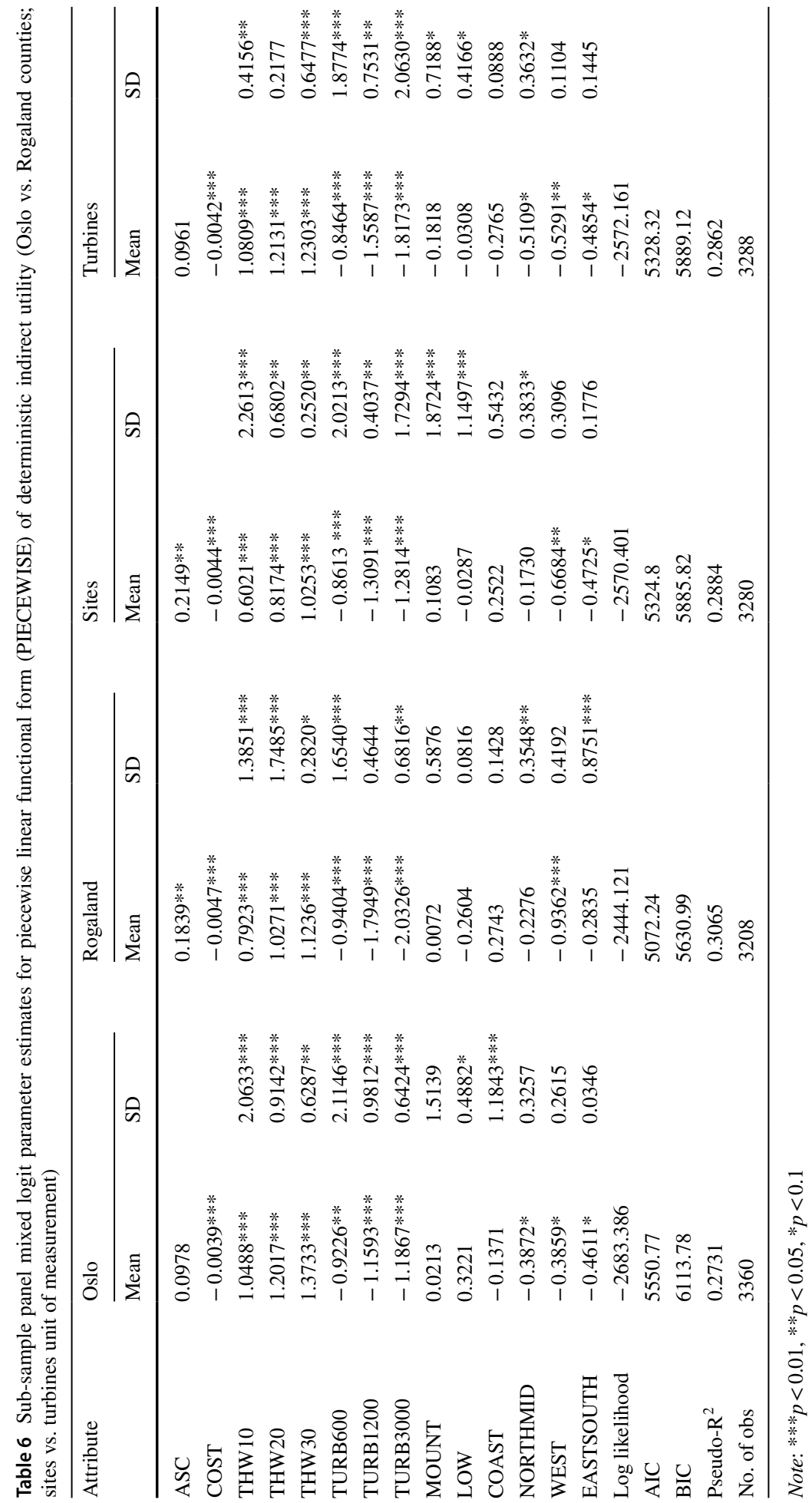




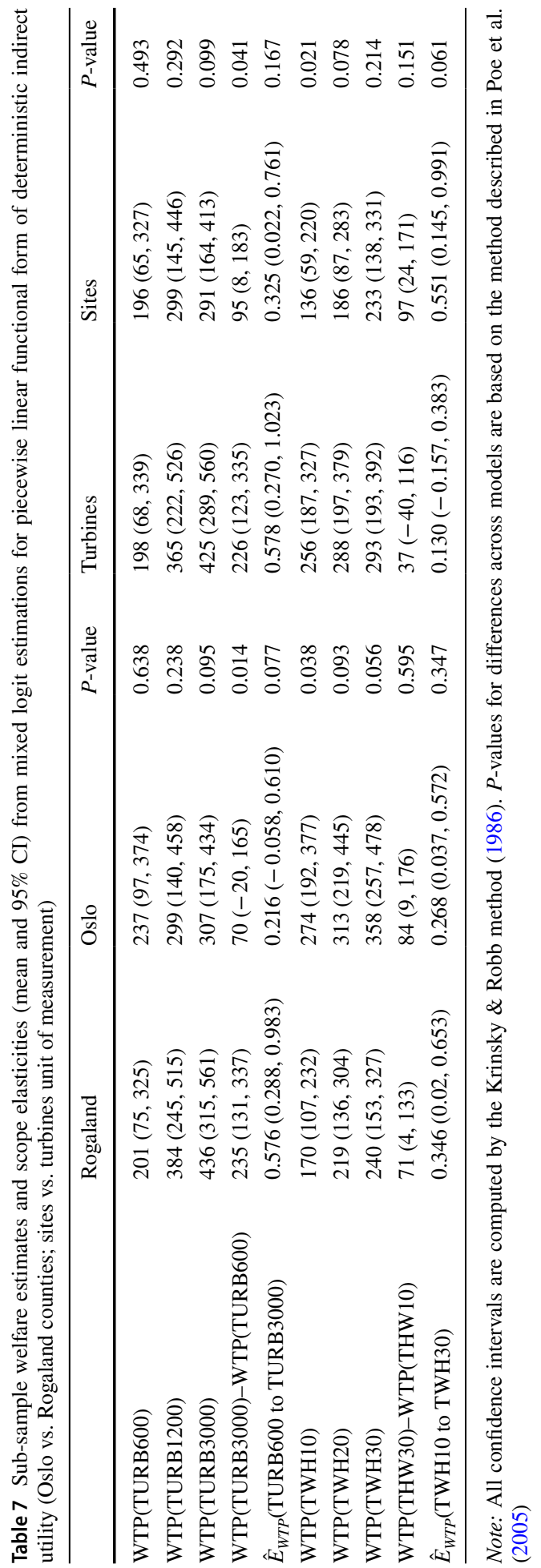




\subsection{Comparison Across Unit of Measurement Subsamples}

Figure 4 and Table 7 summarize WTP and scope elasticity estimates for the two unit of measurement subsamples, while the underlying panel mixed logit results can be found in Table 6. The estimated models are referred to as TURBINES and SITES, respectively. Bear in mind that the only difference between the two DCE versions was the unit of measurement for the wind power attribute. Specifically, the number of wind turbines in one version versus the number of production sites in the other, where one production site was described as comprising thirty wind turbines. The WTP estimates for the wind power attribute are reported on a per turbine basis for comparison.

Figure 4 shows the scope lines overall to be upward sloping, suggesting presence of scope sensitivity. However, the scope line associated with WTP to avoid wind turbines is flatter and non-monotonic in the SITES model, while the scope line associated with WTP for new renewable energy production is flatter in the TURBINES model. These visual patterns are reflected in the estimated scope elasticities reported in Table 7. $\hat{E}_{W T P}$ for avoiding new wind turbines is 0.578 in TURBINES versus 0.325 in SITES, while $\hat{E}_{W T P}$ for new renewable energy production is 0.551 in SITES versus 0.130 in TURBINES. While the former difference is not statistically significant $(P$-value $=0.167)$, the latter is significant at a $10 \%$ level $(P$-value $=0.061)$. Interestingly, the TURBINES model in general yields higher WTP estimates than the SITES model. For example, the difference in WTP to avoid 3000 vs. 600 wind turbines is NOK 226 in the TURBINES model and NOK 95 in the SITES model. The difference across models is statistically significant with $P$-value $=0.041$.

Contrary to our tentative a priori expectation, it appears that the choice of unit of measurement for a key attribute, which in our case is the one that reflects deployment of wind power in Norway, influences welfare estimates and scope elasticities. One potential explanation for the observed difference could be that wind power turbines may invoke stronger associations to negative environmental impacts than the term wind power production sites. Interestingly, the unit of measurement for the wind power attribute also seems to have an impact on the analysis of other attributes of interest, in our case, new renewable energy production. In combination, these findings suggest that choice of attribute representation may influence scope inferences in DCE studies, even when the difference in the available metrics may seem innocuous from a design perspective. While the influence of attribute translations (Hertwig and Grüne-Yanoff 2017; Ungemach et al. 2018) has not been a primary focus of this paper, we are not aware of prior explorations of this topic in the environmental valuation literature, at least not in the context of scope sensitivity analysis.

\subsection{Subsample Results in WTP Space}

We conduct robustness checks of the findings in 5.2 and 5.3 by re-estimating the subsample models in WTP space with lognormal cost parameter (Train and Weeks 2005). Estimated WTPs and scope elasticities results are summarized in appendix Tables 10 and 11. The results are generally similar to those reported above with respect to WTP and elasticity magnitudes and comparisons across geographic subsamples (ROGALAND vs. OSLO) and unit of measurement subsamples (TURBINES vs. SITES). One difference is that estimation in WTP space appears to yield tighter confidence intervals around the estimates, which amplifies the differences across the subsamples. There is also a tendency towards slightly higher, albeit still inelastic, scope elasticity estimates in WTP space. For example, $\hat{E}_{W T P}$ for wind turbines in the OSLO model is 0.444 in WTP space versus 0.216 in preference space. 
However, due to the imprecision of the latter, this difference in not statistically significant $(P$-value $=0.110)$. A notable exception is that $\hat{E}_{W T P}$ for wind turbines is insignificant in the SITES model estimated in WTP space. The estimate of 0.021 is statistically different from the estimate of 0.325 from the corresponding model estimated in preference space with fixed cost parameter $(P$-value $=0.037)$. This finding suggests that econometric model assumptions and specifications may also affect estimated scope effects.

\section{Concluding Remarks}

Investigating the significance of scope sensitivity remains an important validity check in SP research, but it is important to make a distinction between statistical and economic significance (Amiran and Hagen 2010; Whitehead 2016; Lopes and Kipperberg 2020). This paper is the first to carry out a systematic investigation of the significance of scope effects in DCE studies using the scope elasticity of WTP concept. Specifically, it provides a conceptual exposition and a twofold empirical analysis. First, we analyze a selection of DCE studies from the environmental valuation literature and derive their implicit scope elasticities. Second, we apply the scope elasticity concept in an analysis of primary data from a DCE on preferences for renewable energy expansions in Norway.

From the literature analysis we observe that explorations of scope sensitivity as a validity check, or for any other reason, are scarce in DCE studies. Furthermore, many studies employ a restrictive linear functional form for deterministic indirect utility, which implies a scope elasticity of one. When more flexible specifications are employed, such as quadratic or piecewise linear, there is a tendency toward inelastic scope sensitivity, i.e., a scope elasticity greater than zero but less than one.

There are several possible explanations for the lack of scope sensitivity focus in DCE research. One obvious explanation is that the DCE design process of identifying salient choice features typically ensures that key attributes are statistically significant in estimation. Related to this is the added statistical precision that comes from the practice of utilizing multiple choice tasks per respondent. However, as pointed out in this paper, statistical significance is not the same as economic significance. It is worth reflecting on the fact that the dearth of scope investigations in the environmental DCE literature coincides with a general lack of attention to functional form and utility-theoretic properties in RUM applications (Hoyos 2010; Mariel et al. 2021). In turn, this deficiency has implications for the ability to differentiate between statistical and economic significance in estimated effects. As observed by Johnston et al. (2017: p. 361): "Many published SP studies facilitate estimation by assuming a utility function that is linear and additively separable (with constant marginal utilities). Although such functions may serve as a useful local first approximation, these implicit assumptions will not always hold. Among the concerns in this area is the likelihood that preferences will exhibit nonlinearity (e.g., diminishing marginal utility or nonconstant marginal rates of substitution between attributes). Such possibilities can be accommodated using richer specifications for preference or welfare functions."

In our own empirical application, we find positive mean preferences for new renewable energy production and negative mean preferences for new wind turbines, ceteris paribus. For example, estimated mean WTP for avoiding 600 and 3000 wind turbines are NOK 256 and NOK 373 per household per month, respectively, in the flexible piecewise linear specification for the full sample. The simulated scope arc-elasticity of WTP between these two attributes levels is 0.288. In general, our estimation results suggest sizeable differences in WTP across attribute levels, with estimated scope elasticities varying between 0.13 and 0.58 , depending on the attribute 
analyzed (new renewable energy or new wind turbines), model specification (quadratic or piecewise linear), geographic subsample (Rogaland County versus Oslo County), and the unit of measurement (wind turbines versus wind power production sites).

While there is no strict, universally applicable benchmark for assessing the economic significance of scope effects, we deem these scope elasticities to be of an adequate and plausible order of magnitude. Thus, the results from our study can be used to inform policy decisions related to renewable energy investments. In particular, the welfare estimates for different levels of wind power expansion can be utilized as valid inputs in benefit-cost analyses and optimization models for the sizing and siting of future wind power in Norway. It may also be possible to employ scope elasticity estimates from our study, or scope elasticities derived from other existing studies, in benefit transfer exercises, provided contextspecific baseline welfare estimates are available.

We end this paper by providing some take-home messages of best practices and directions for future research. First, we think it should be standard practice for DCE practitioners to include explicit statements regarding internal validity in general and scope sensitivity in particular in reporting from their studies. Second, the selection of functional form of the underlying value function (e.g., the deterministic component of indirect utility in the standard RUM framework) should be carefully explained and justified. The piecewise linear specification recommended by Layton and Brown (2000) and employed in our own analysis provides a high degree of flexibility, while the simple linear functional form should be avoided. Third, formal scope sensitivity diagnostics should be carried out for all quantitative attributes. Specifically, we recommend that scope elasticity estimates are reported as part of the standard output, i.e., alongside the usual econometric estimation results and monetary value estimates. Fourth, ex ante DCE design adaptations should be made to facilitate ex post scope sensitivity analysis. In particular, the selection of units of measurement, attribute levels, and experimental design must enable estimation of models that relax the assumption of constant marginal utility and facilitate flexible identification of scope elasticities.

A fruitful general direction for future research on scope sensitivity in DCE is to systematically examine how scope elasticities are influenced by various conceptual, methodological, and empirical dimensions. In this paper, we limited our data analysis to the mean scope elasticities and examined how these varied across attributes, geographic sub-samples, and experimental variation in the wind power attribute. However, scope elasticities are likely to vary across individuals, valuation contexts, and a multitude of choice architecture dimensions. For this reason, one specific direction for future research would be to expand the literature analysis in this paper with the aim of compiling a large dataset of extracted scope elasticities, which could then lend itself to meta-regression analysis. Such analysis could be limited to DCEs or include CV studies. A second specific direction for future research would be to analyze determinants of individual-specific scope elasticities. For example, it is possible to extract conditional, individual-specific WTP estimates from panel mixed logit estimations, which, in turn, can be utilized to predict individual-specific scope elasticities. By linking these elasticities to respondent-level information, one would be able to explore a wide range of conceptual hypotheses on factors that may influence scope sensitivity (e.g., income, age, education, knowledge, perceptions, familiarity, etc.) through auxiliary regressions. Such analysis would be particularly attractive if it involved several datasets spanning multiple attributes from various valuation contexts. A third specific direction for future research would be to explore potential differences in sensitivity to scope across experimental variations in the experimental design. For example, a so-called design-of-design approach (e.g., Hensher 2006; Weller et al. 2014) could be taken to analyze how choice architecture and researcher's design decisions influence welfare estimates per se and the estimated scope elasticities. Ultimately, an important aim of all this research would be to better understand the underlying reasons for scope (in)sensitivity and improve designs to better capture true preferences for 
environmental change in future SP research. This is also crucial for making resulting welfare estimates (more) useful for benefit-cost analysis, both in applications of the original estimates and in benefit transfer exercises.

Finally, we emphasize that we believe that true scope sensitivity varies naturally across people and valuation objects in the real world. Consequently, it is not possible to define a single threshold value from which internal scope validity of a study can be inferred. Therefore, we believe that the adequacy, plausibility, and economic significance of estimated scope effects must be assessed on a case-by-case basis.

\section{Appendix}

\section{Proof: Unit Elastic Scope Elasticity for Linear Indirect Utility Specifications}

Let $V_{j}=\alpha_{j}+\boldsymbol{\beta}_{q} \boldsymbol{q}_{j}+\beta_{M}\left(M-\boldsymbol{B}_{j}\right)$ without loss of generality. Then marginal willingness to pay for a change in element $s$ of the $\boldsymbol{q}$-vector is: $\operatorname{WTP}\left(q_{s}\right)=\frac{\beta_{q_{S}}}{\beta_{M}}$, which is constant.

Willingness to pays for two discrete changes, $\Delta_{s}^{A}=q_{s}^{A}-q_{s}^{0}$ and $\Delta_{s}^{B}=q_{s}^{B}-q_{s}^{0}$, are therefore: $W T P^{A}=\frac{\beta_{q_{S}}}{\beta_{M}} \cdot \Delta_{s}^{A}$ and $W T P^{B}=\frac{\beta_{q_{S}}}{\beta_{M}} \cdot \Delta_{s}^{B}$, respectively.

Hence, the scope arc-elasticity between the two WTPs is:

$$
\bar{E}_{W T P} \equiv \frac{\% \Delta W T P}{\% \Delta q_{s}}=\left(\frac{\frac{\beta_{q_{S}}}{\beta_{M}} \cdot \Delta_{s}^{B}-\frac{\beta_{q_{S}}}{\beta_{M}} \cdot \Delta_{s}^{A}}{\left.\frac{\beta_{q_{S}}}{\beta_{M}} \cdot \Delta_{s}^{B}+\frac{\beta_{q_{S}}}{\beta_{M}} \cdot \Delta_{s}^{A}\right) / 2}\right) /\left(\frac{\Delta_{s}^{B}-\Delta_{s}^{A}}{\left(\Delta_{s}^{B}+\Delta_{s}^{A}\right) / 2}\right)=1
$$

See Table 8, 9, 10 and 11.

Table 8 Basic descriptive statistics for full sample, Oslo subsample versus Oslo population, Rogaland subsample versus Rogaland population, and turbine subsample versus sites subsample

\begin{tabular}{|c|c|c|c|c|c|c|c|c|}
\hline \multicolumn{2}{|c|}{ Sociodemographic profile } & \multirow{2}{*}{$\begin{array}{l}\text { Full sample } \\
49 \%\end{array}$} & \multirow{2}{*}{$\begin{array}{l}\text { Oslo } \\
46 \%\end{array}$} & \multirow{2}{*}{$\begin{array}{l}\text { Oslo population } \\
50 \%\end{array}$} & \multirow{2}{*}{$\begin{array}{l}\text { Rogaland } \\
51 \%\end{array}$} & \multirow{2}{*}{$\begin{array}{l}\begin{array}{l}\text { Rogaland } \\
\text { population }\end{array} \\
51 \%\end{array}$} & \multirow{2}{*}{$\begin{array}{l}\text { Turbines } \\
48 \%\end{array}$} & \multirow{2}{*}{$\begin{array}{l}\text { Sites } \\
49 \%\end{array}$} \\
\hline Gender & Male & & & & & & & \\
\hline & Female & $51 \%$ & $54 \%$ & $50 \%$ & $49 \%$ & $49 \%$ & $52 \%$ & $51 \%$ \\
\hline Income & $\begin{array}{l}\text { Mean } \\
\text { household } \\
\text { income } \\
(1000 \\
\text { NOK })\end{array}$ & 576 & 564 & 624 & 588 & 735 & 567 & 585 \\
\hline Education & $\begin{array}{l}\text { Higher } \\
\text { education, } \\
\text { (Bachelor } \\
\text { or more) }\end{array}$ & $59 \%$ & $70 \%$ & $31 \%$ & $47 \%$ & $23 \%$ & $62 \%$ & $53 \%$ \\
\hline Age & Mean age & 43 & 41 & 44 & 44 & 38 & 42 & 43 \\
\hline Region & Oslo & $51 \%$ & $100 \%$ & $100 \%$ & $0 \%$ & $0 \%$ & $51 \%$ & $51 \%$ \\
\hline & Rogaland & $49 \%$ & $0 \%$ & $0 \%$ & $100 \%$ & $100 \%$ & $49 \%$ & $49 \%$ \\
\hline
\end{tabular}




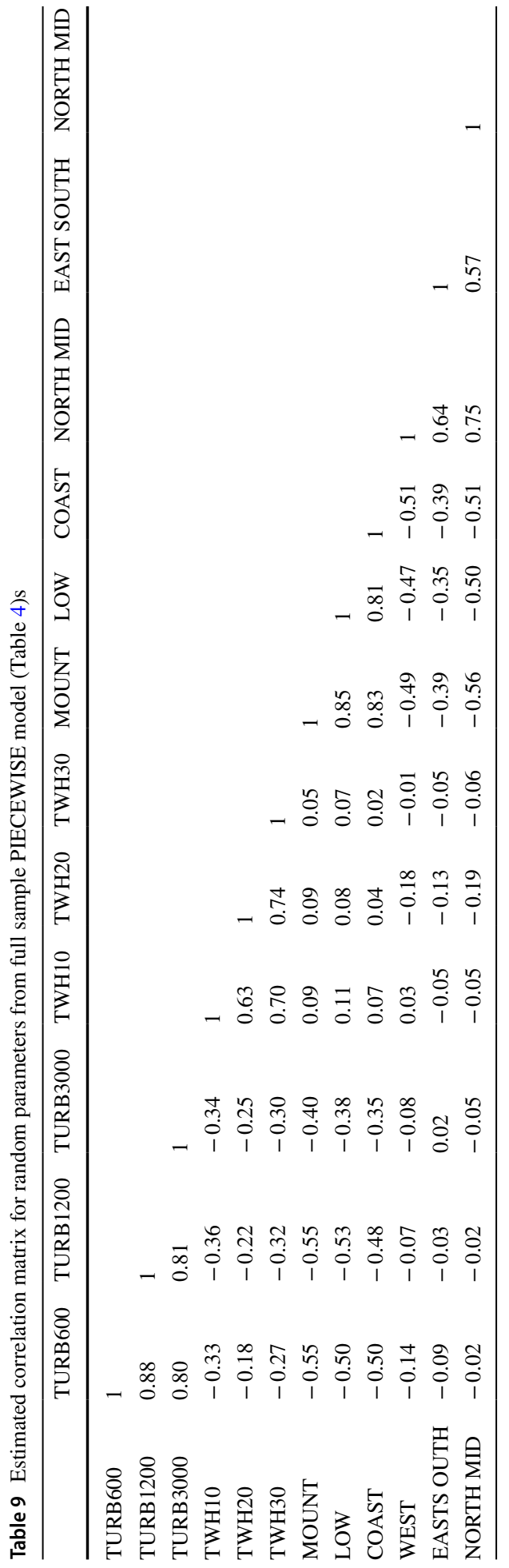




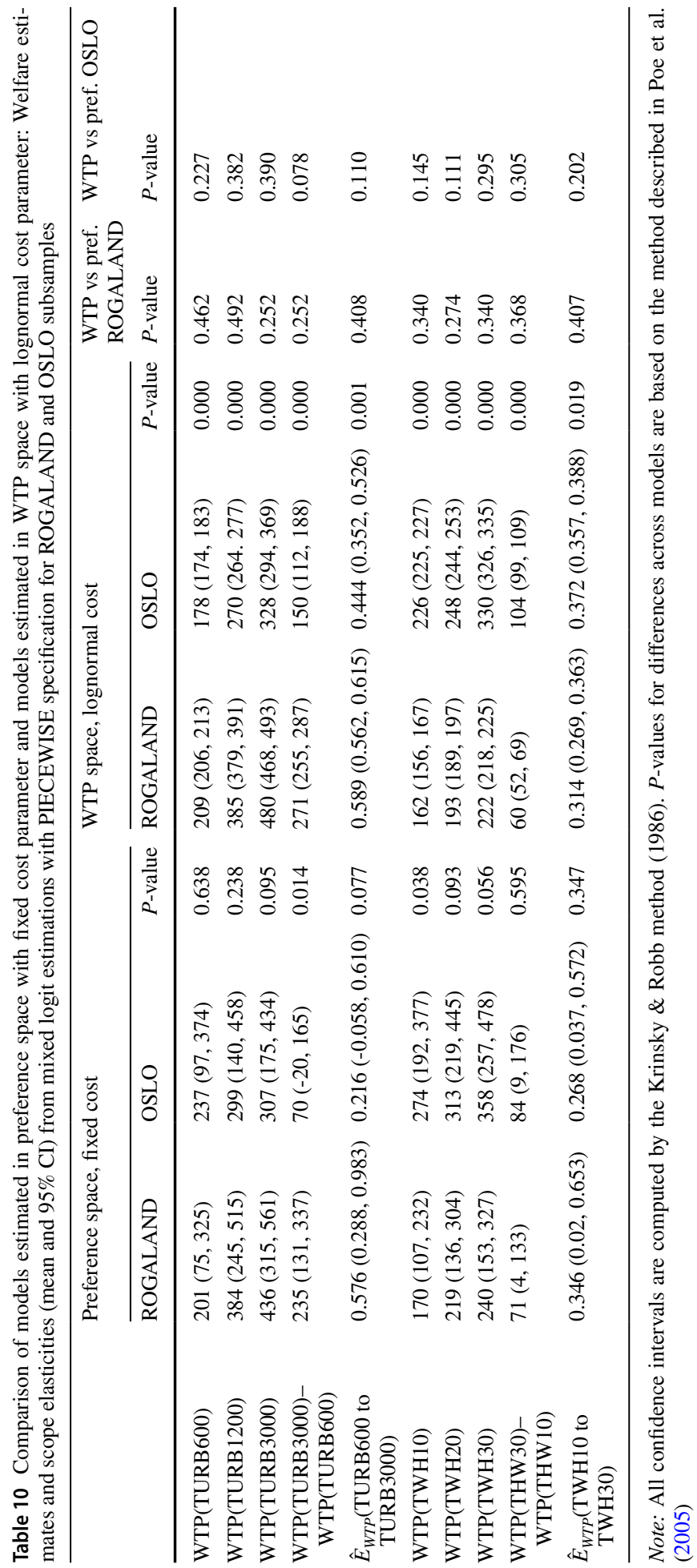




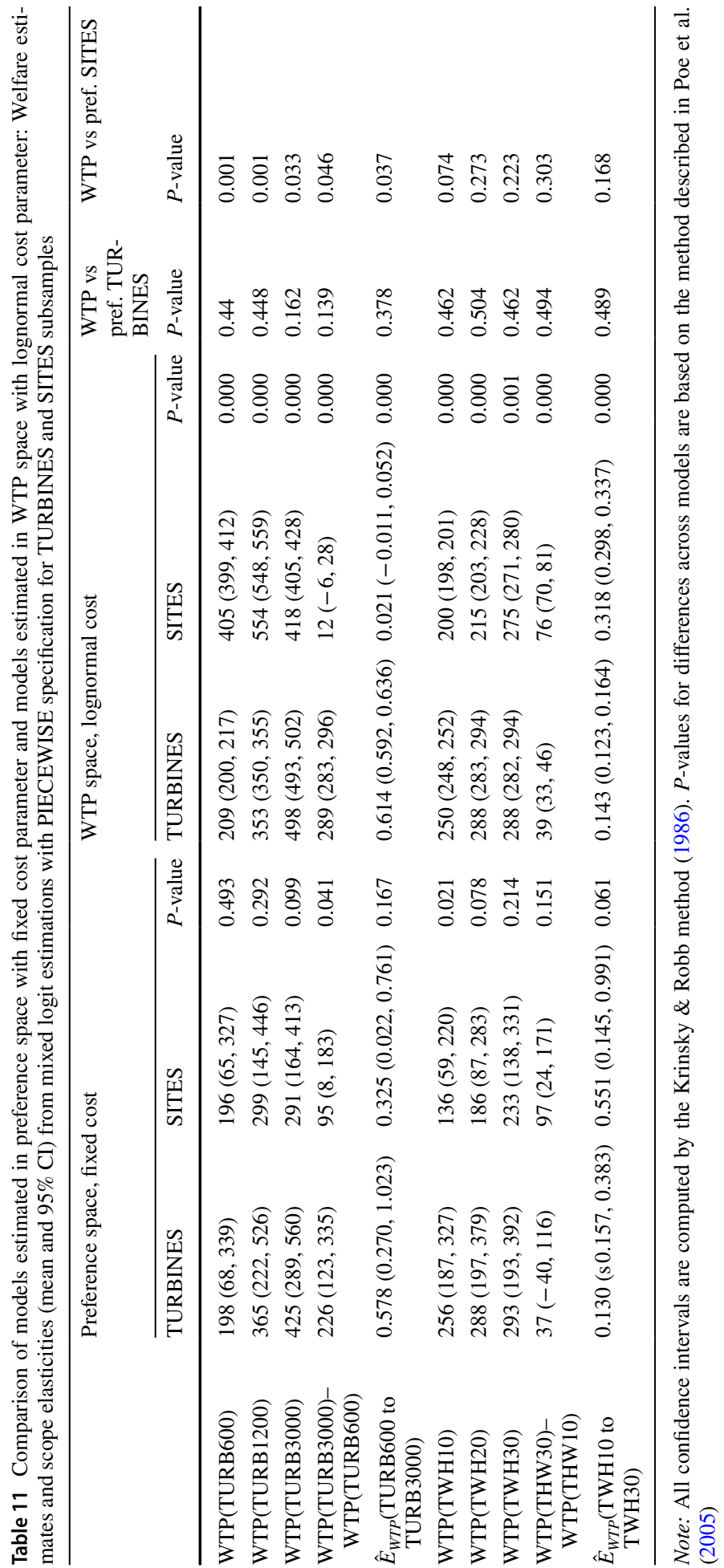


Supplementary Information The online version contains supplementary material available at https://doi. org/10.1007/s10640-021-00577-7.

Funding Open access funding provided by University Of Stavanger. The research was funded by the Research Council of Norway, grant numbers 267909 (WINDLAND) and 255777 (COAST-BENEFIT).

Open Access This article is licensed under a Creative Commons Attribution 4.0 International License, which permits use, sharing, adaptation, distribution and reproduction in any medium or format, as long as you give appropriate credit to the original author(s) and the source, provide a link to the Creative Commons licence, and indicate if changes were made. The images or other third party material in this article are included in the article's Creative Commons licence, unless indicated otherwise in a credit line to the material. If material is not included in the article's Creative Commons licence and your intended use is not permitted by statutory regulation or exceeds the permitted use, you will need to obtain permission directly from the copyright holder. To view a copy of this licence, visit http://creativecommons.org/licenses/by/4.0/.

\section{References}

Adamowicz W, Louviere J, Williams M (1994) Combining revealed and stated preference methods for valuing environmental amenities. J Environ Econ Manag 26(3):271-292

Adamowicz W, Boxall P, Williams M, Louviere J (1998) Stated preference approaches for measuring passive use values: choice experiments and contingent valuation. Am J Agr Econ 80(1):64-75

Alvarez-Farizo B, Hanley N (2002) Using conjoint analysis to quantify public preferences over the environmental impacts of wind farms. an example from Spain. Energy Policy 30:107-116

Amiran EY, Hagen DA (2010) The scope trials: Variation in sensitivity to scope and WTP with directionally bounded utility functions. J Environ Econ Manag 59(3):293-301

Ando AW, Cadavid CL, Netusil NR, Parthum B (2020) Willingness-to-volunteer and stability of preferences between cities: estimating the benefits of stormwater management. J Environ Econ Manag 99:102274

Arrow K, Solow R, Portney PR, Leamer EE, Radner R, Schuman H (1993) Report of the NOAA panel on contingent valuation. Fed Reg 58(10):4601-4614

Arrow K, Leamer E, Schuman H, Solow R (1994) Appendix D in Comments on Proposed NOAA/DOI Regulations on Natural Resource Damage Assessment. US Environmental Protection Agency (October).

Badura T, Ferrini S, Burton M, Binner A, Bateman IJ (2020) Using individualised choice maps to capture the spatial dimensions of value within choice experiments. Environ Resour Econ 75(2):297-322

Bergmann A, Hanley N, Wright R (2006) Valuing the attributes of renewable energy investments. Energy Policy 34(9):1004-1014

Berrens RP, Bohara AK, Silva CL, Brookshire D, McKee M (2000) Contingent values for New Mexico instream flows: With tests of scope, group-size reminder and temporal reliability. J Environ Manage 58(1):73-90

Borchers A, Duke J, Parsons G (2007) Does willingness to pay for green energy differ by source? Energy Policy 35(6):3327-3334

Börger T, Hooper TL, Austen MC (2015) Valuation of ecological and amenity impacts of an offshore windfarm as a factor in marine planning. Environ Sci Policy 54:126-133

Borzykowski N, Baranzini A, Maradan D (2018) Scope effects in contingent valuation: does the assumed statistical distribution of WTP matter? Ecol Econ 144:319-329

Boxall PC, Adamowicz WL, Swait J, Williams M, Louviere J (1996) A comparison of stated preference methods for environmental valuation. Ecol Econ 18(3):243-253

Brennan N, Van Rensburg TM (2016) Wind farm externalities and public preferences for community consultation in Ireland: a discrete choice experiments approach. Energy Policy 94:355-365

Brennan N, van Rensburg TM (2020) Public preferences for wind farms involving electricity trade and citizen engagement in Ireland. Energy Policy 147:111872

Brökel T, Alfken C (2015) Gone with the wind? the impact of wind turbines on tourism demand. Energy Policy 86:506-519

Burrows J, Newman R, Genser J, Plewes J (2017) Do contingent valuation estimates of willingness to pay for non-use environmental goods pass the scope test with adequacy? A review of the evidence from empirical studies in the literature. In Contingent Valuation of Environmental Goods. Edward Elgar Publishing. 
Carson RT, Flores NE, Meade NF (2001) Contingent valuation: controversies and evidence. Environ Resource Econ 19(2):173-210

Cicia G, Cembalo L, Del Giudice T, Palladino A (2012) Fossil energy versus nuclear, wind, solar and agricultural biomass: Insights from an Italian national survey. Energy Policy 42:59-66

Dalton T, Weir M, Calianos A, D’Aversa N, Livermore J (2020) Recreational boaters' preferences for boating trsips associated with offshore wind farms in US waters. Mar Policy 122:104216

Dellaert BG, Swait J, Adamowicz WLV, Arentze TA, Bruch EE, Cherchi E, Chorus C, Donkers B, Feinberg FM, Marley AA, Salisbury LC (2018) Individuals' decisions in the presence of multiple goals. Cust Needs Solut 5(1-2):51-64

Desvousges WH, Johnson FR, Dunford RW, Boyle KJ, Hudson SP, Wilson KN (1992) Measuring nonuse damages using contingent valuation: an experimental evaluation of accuracy. Research Triangle Park, NC

Diamond PA, Hausman JA (1994) Contingent valuation: is some number better than no number? J Econ Perspect 8(4):45-64

Drechsler M, Ohl C, Meyerhoff J, Eichhorn M, Monsees J (2011) Combining spatial modeling and choice experiments for the optimal spatial allocation of wind turbines. Energy Policy 39(6):3845-3854

Dugstad A, Grimsrud K, Kipperberg G, Lindhjem H, Navrud S (2020) Acceptance of wind power development and exposure-Not-in-anybody's-backyard. Energy Policy 147:111780

Ek K, Matti S (2015) Valuing the local impacts of a large scale wind power establishment in northern Sweden: public and private preferences toward economic, environmental and sociocultural values. J Environ Plan Manage 58(8):1327-1345

Ek K, Persson L (2014) Wind farms-Where and how to place them? A choice experiment approach to measure consumer preferences for characteristics of wind farm establishments in Sweden. Ecol Econ 105:193-203

Fimereli E, Mourato S, Pearson PJG (2008) Measuring preferences for low-carbon energy technologies in South-East England: the case of electricity generation.

Fimereli E, Mourato S (2013) Assessing the effect of energy technology labels on preferences. J Environ Econ Policy 2(3):245-265

Freeman AM III, Herriges JA, Kling CL (2014) The measurement of environmental and resource values: theory and methods. Routledge

García JH, Cherry TL, Kallbekken S, Torvanger A (2016) Willingness to accept local wind energy development: does the compensation mechanism matter? Energy Policy 99:165-173

Gibbons S (2015) Gone with the wind: valuing the visual impacts of wind turbines through house prices. J Environ Econ Manag 72:177-196

Goldberg I, Roosen J (2007) Scope insensitivity in health risk reduction studies: a comparison of choice experiments and the contingent valuation method for valuing safer food. $\mathrm{J}$ Risk Uncertain 34(2):123-144

Haab TC, Interis GM, Petrolia DR, Whitehead JC (2013) From hopeless to curious? thoughts on Hausman's "dubious to hopeless" critique of contingent valuation. Appl Econ Perspect Policy 35(4):593-612

Hausman J (2012) Contingent valuation: from dubious to hopeless. J Econ Perspect 26(4):43-56

Heberlein TA, Wilson MA, Bishop RC, Schaeffer NC (2005) Rethinking the scope test as a criterion for validity in contingent valuation. J Environ Econ Manag 50(1):1-22

Hensher DA (2006) How do respondents process stated choice experiments? attribute consideration under varying information load. J Appl Economet 21:861-878

Hensher DA, Rose JM, Greene WH (2005) Applied choice analysis: a primer. Cambridge University Press

Hertwig R, Grüne-Yanoff T (2017) Nudging and boosting: steering or empowering good decisions. Perspect Psychol Sci 12(6):973-986

Holmes TP, Adamowicz WL, Carlsson F (2017) Choice experiments. A primer on nonmarket valuation (pp. 133-186). Springer, Dordrecht.

Hoyos D (2010) The state of the art of environmental valuation with discrete choice experiments. Ecol Econ 69(8):1595-1603

Hynes S, Chen W, Vondolia K, Armstrong C, O'Connor E (2020) Valuing the ecosystem service benefits from kelp forest restoration: a choice experiment from Norway. Ecol Econ 179:106833

Johnston RJ, Boyle KJ, Adamowicz W, Bennett J, Brouwer R, Cameron TA, Hanemann WM, Hanley N, Ryan M, Scarpa R, Tourangeau R, Vossler CA (2017) Contemporary guidance for stated preference studies. J Assoc Environ Resour Econ 4(2):319-405

Kahneman D, Knetsch JL (1992) Valuing public goods: the purchase of moral satisfaction. J Environ Econ Manag 22(1):57-70

Kahneman, D. (1986). Comments on the contingent valuation method. Valuing environmental goods: An assessment of the contingent valuation method, 185-193. 
Kling CL, Phaneuf DJ, Zhao J (2012) From Exxon to BP: has some number become better than no number? J Econ Perspect 26(4):3-26

Kosenius A-K, Ollikainen M (2013) Valuation of environmental and societal trade-offs of renewable energy sources. Energy Policy 62:1148-1156

Krekel C, Zerrahn A (2017) Does the presence of wind turbines have negative externalities for people in their surroundings? evidence from well-being data. J Environ Econ Manag 82:221-238

Krinsky I, Robb AL (1986) On approximating the statistical properties of elasticities. Rev Econ Stat 68:715-719

Krutilla JV (1967) Conservation reconsidered. Am Econ Rev 57(4):777-786

$\mathrm{Ku}$ SJ, Yoo SH (2010) Willingness to pay for renewable energy investment in Korea: a choice experiment study. Renew Sustain Energy Rev 14(8):2196-2201

Kuhfeld WF (2010) Marketing research methods in SAS - experimental design, choice, conjoint, and graphical techniques. SAS Institute Inc., Cary

Ladenburg J, Dubgaard A (2009) Preferences of coastal zone user groups regarding the siting of offshore wind farms. Ocean Coast Manag 52(5):233-242

Landry CE, Allen T, Cherry T, Whitehead JC (2012) Wind turbines and coastal recreation demand. Resour Energy Econ 34(1):93-111

Layton DF, Brown G (2000) Heterogeneous preferences regarding global climate change. Rev Econ Stat 82(4):616-624

Lew DK, Wallmo K (2011) External tests of scope and embedding in stated preference choice experiments: an application to endangered species valuation. Environ Resour Econ 48(1):1-23

Liebe U, Glenk K, Oehlmann M, Meyerhoff J (2015) Does the use of mobile devices (tablets and smartphones) affect survey quality and choice behaviour in web surveys? J Choice Model 14:17-31

Lindhjem H, Navrud S, Braathen NA, Biausque V (2011) Valuing mortality risk reductions from environmental, transport, and health policies: a global meta-analysis of stated preference studies. Risk Anal Int J 31(9):1381-1407

Longo A, Markandya A, Petrucci M (2008) The internalization of externalities in the production of electricity: willingness to pay for the attributes of a policy for renewable energy. Ecol Econ 67(1):140-152

Lopes AF, Kipperberg G (2020) Diagnosing insensitivity to scope in contingent valuation. Environ Resour Econ 77(1):191-216

Louviere JJ, Hensher DA, Swait JD (2000) Stated choice methods: analysis and applications. Cambridge University Press

Mariel P, Meyerhoff J, Hess S (2015) Heterogeneous preferences toward landscape externalities of wind turbines-combining choices and attitudes in a hybrid model. Renew Sustain Energy Rev 41:647-657

Mariel P, Hoyos D, Meyerhoff J, Czajkowski M, Dekker T, Glenk K, Jacobsen JB, Liebe U, Olsen SB, Sagebiel J, Thiene M (2021) Environmental valuation with discrete choice experiments: Guidance on design, implementation and data analysis (p. 129). Springer Nature.

Mattmann M, Logar I, Brouwer R (2016) Wind power externalities: a meta-analysis. Ecol Econ 127:23-36

McCloskey DN, Ziliak ST (1996) The standard error of regressions. J Econ Lit 34(1):97-114

Meyerhoff J, Ohl C, Hartje V (2010) Landscape externalities from onshore wind power. Energy Policy 38(1):82-92

Meyerhoff J, Oehlmann M, Weller P (2015) The influence of design dimensions on stated choices in an environmental context. Environ Resour Econ 61(3):385-407

Mitchell RC, Carson RT (1989) Using surveys to value public goods: the contingent valuation method. Resources for the Future.

Navrud S, Bråten KG (2007) Consumers' preferences for green and brown electricity: a choice modelling approach. Revue D'économie Politique 117(5):795-811

NVE (2019) Forslag til nasjonal ramme for vindkraft. 12-2019. (Eng: Proposal for National Plan for Wind Power, The Norwegian Water Resources and Energy Directorate) Norges Vassdrags- Og Energidirektorat.

Peri E, Becker N, Tal A (2020) What really undermines public acceptance of wind turbines? a choice experiment analysis in Israel. Land Use Policy 99:105113

Poe GL, Giraud KL, Loomis JB (2005) Computational methods for measuring the difference of empirical distributions. Am J Agr Econ 87(2):353-365

Rakotonarivo OS, Schaafsma M, Hockley N (2016) A systematic review of the reliability and validity of discrete choice experiments in valuing non-market environmental goods. J Environ Manage 183:98-109

Revelt D, Train K (1998) Mixed logit with repeated choices: households' choices of appliance efficiency level. Rev Econ Stat 80(4):647-657

Ruud P (1996) Approximation and simulation of the multinomial probit model: an analysis of covariance matrix estimation. Department of Economics, Berkeley, pp 1-17 
Sandorf ED (2019) Did you miss something? inattentive respondents in discrete choice experiments. Environ Resour Econ 73(4):1197-1235

Schlüter M, Baeza A, Dressler G, Frank K, Groeneveld J, Jager W, Janssen MA, McAllister RJ, Müller B, Orach K, Schwarz N, Wijermans N (2017) A framework for mapping and comparing behavioural theories in models of social-ecological systems. Ecol Econ 131:21-35

Thorbecke E (2004) Economic and statistical significance: comments on "Size Matters." J Socio-Econ 33(5):571-575

Train KE (2009) Discrete choice methods with simulation. Cambridge University Press

Train K, Weeks M (2005) Discrete choice models in preference space and willingness-to-pay space. In Applications of simulation methods in environmental and resource economics (pp. 1-16). Springer, Dordrecht.

Ungemach C, Camilleri AR, Johnson EJ, Larrick RP, Weber EU (2018) Translated attributes as choice architecture: Aligning objectives and choices through decision signposts. Manage Sci 64(5):2445-2459

Vecchiato D (2014) How do you like wind farms? Understanding people's preferences about new energy landscapes with choice experiments. Aestimum 15-37.

Weller P, Oehlmann M, Mariel P, Meyerhoff J (2014) Stated and inferred attribute non-attendance in a design of designs approach. J Choice Model 11:43-56

Westerberg V, Jacobsen JB, Lifran R (2013) The case for offshore wind farms, artificial reefs and sustainable tourism in the French Mediterranean. Tour Manage 34:172-183

Whitehead JC (2016) Plausible responsiveness to scope in contingent valuation. Ecol Econ 128:17-22

Whitehead JC, Haab TC, Huang JC (1998) Part-whole bias in contingent valuation: will scope effects be detected with inexpensive survey methods? South Econ J 65:160-168

Wilson GA, Dyke SL (2016) Pre-and post-installation community perceptions of wind farm projects: the case of Roskrow Barton (Cornwall, UK). Land Use Policy 52:287-296

Zerrahn A (2017) Wind power and externalities. Ecol Econ 141:245-260

Zhao M, Johnston RJ, Schultz ET (2013) What to value and how? Ecological indicator choices in stated preference valuation. Environ Resour Econ 56(1):3-25

Publisher's Note Springer Nature remains neutral with regard to jurisdictional claims in published maps and institutional affiliations. 